\title{
NUEVA ESPECIE DE TABULADO DEL DEVÓNICO INFERIOR DE ARGENTINA
}

\author{
Esperanza FERNÁNDEZ-MARTÍNEZI, Yves PLUSQUELLEC ${ }^{2}$, \\ Francis TOURNEUR ${ }^{3}$ y Zarela HERRERA ${ }^{4}$ \\ I Universidad de León. Departamento de Ingeniería Minera. c/ Jesús Rubio, 2. 24071 León. España. E- \\ mail: dimefm@unileon.es \\ 2 Université de Bretagne Occidentale. Laboratoire de Paléontologie et Stratigraphie du Paléozoïque. \\ Faculté des Sciences. 6, avenue Le Gorgeu. 29285 Brest Cedex. Francia. \\ ${ }^{3}$ Université Catholique de Louvain. Unité de Paléontologie et Paléogéographie, 3 place L. Pasteur. B- \\ 1348 Louvain-la-Neuve. Bélgica. \\ * CONICET. Servicio Geológico, SEGEMAR (Delegación Córdoba). Av. Poeta Lugones 161. (5000) \\ Córdoba. Argentina. E-mail: mineria@si.cordoba.com.ar
}

Fernández-Martínez, E., Plusquellec, Y., Tourneur, F. y Herrera, Z. 1999. Nueva especie de tabulado del Devónico Inferior de Argentina. [A new species of Tabulate coral from the Lower Devonian of Argentina]. Revista Española de Paleontología, 14 (1), 37-57. ISSN 0213-6937.

\begin{abstract}
A new species of Tabulate coral, Parastriatopora sanjuanina, coming from two localities sited in the southern part of the Argentinian Precordillera is decribed. The studied material was collected in some calcareous levels near the base of the Talacasto Fm., lower Lochkhovian in age. This species is assigned to the genus Parastriatopora and is characterized by a small axial zone made up of some few corallites and by the main development of a compact peripheral rim in the mature branches. The outer surface of these branches shows the calices bearing between eight and twelve ridges separated by eight rounded hollows.
\end{abstract}

Keywords: Tabulate corals, Systematics, Devonian, Argentina.

\section{RESUMEN}

Se describe una nueva especie de coral tabulado, Parastriatopora sanjuanina, procedente de dos localidades situadas en la zona sur de la Precordillera Argentina. El material estudiado procede de varios niveles carbonatados situados en la base de la Fm. Talacasto cuya edad es Lochkoviense inferior. La nueva especie se asigna al género Parastriatopora y está caracterizada por la presencia de una zona axial reducida, constituida por un escaso número de coralitas y por el importante desarrollo de un reborde periférico compacto en las ramas maduras. Externamente, las ramas muestran cálices ornamentados por entre ocho y doce crestas separadas por ocho depresiones puntiformes.

Palabras clave: Corales Tabulados, Sistemática, Devónico, Argentina.

\section{INTRODUCCIÓN}

Dentro del proyecto de investigación $\mathrm{N}^{\circ} 3475 / 95$, subsidiado por el Consejo de Investigaciones Científicas (CONICOR) de la Provincia de Córdoba, Argentina y que tiene por objetivo el estudio paleobiogeográfico, bioestratigráfico y paleoambiental del Devónico de la Precordillera Argentina, se han realizado varios trabajos de campo que permitieron ampliar el conocimiento sobre las secuencias devónicas de la Formación Talacasto y recolectar abundante material fósil, entre el que se encuentran varios ejemplares atribuibles a corales tabulados.

En este marco, el objetivo central de este trabajo es dar a conocer una nueva especie de coral tabulado reconocida para el Devónico de la Precordillera Argentina. Con este estudio se realiza un aporte al conocimiento sistemático de las faunas devónicas sudamericanas y principalmente de las argentinas, información necesaria que permitirá ampliar el 


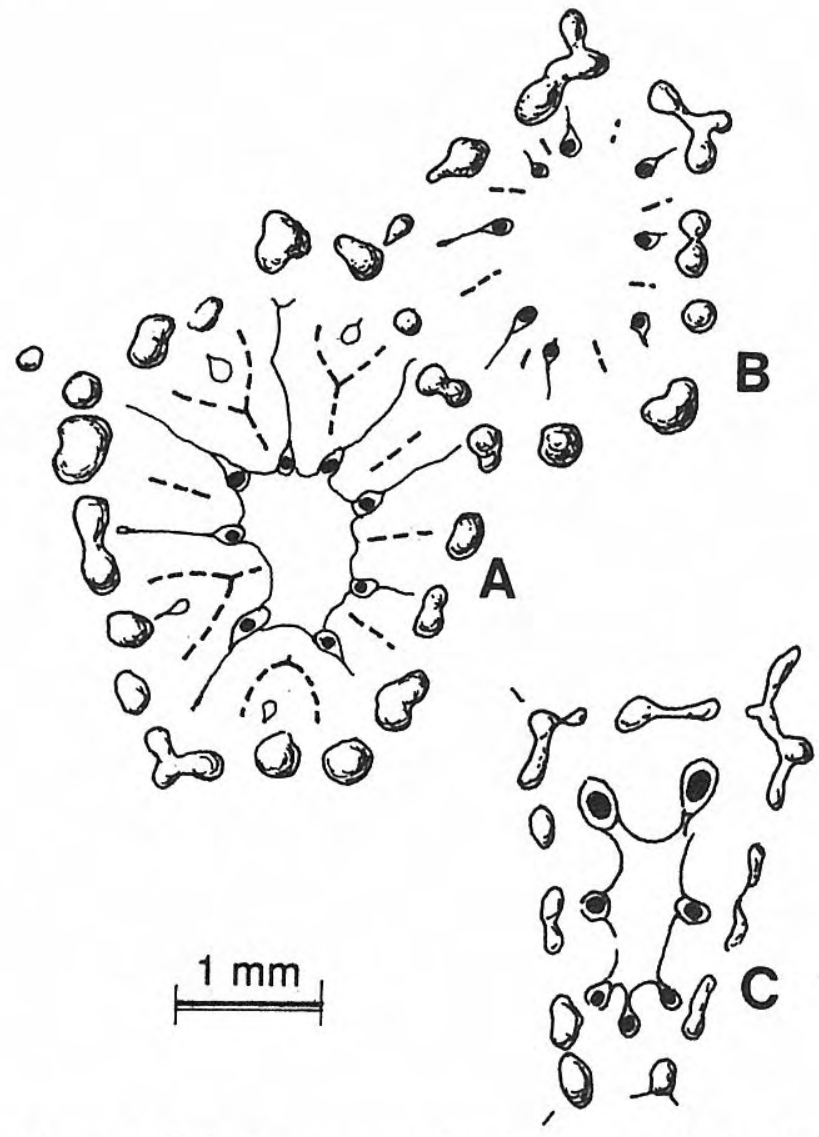

Figura 1. Dibujo esquemático de la morfología de los cálices de Parastriatopora sanjuanina n. sp. Las depresiones puntiformes situadas en la base del cáliz están marcadas por un círculo negro, las crestas desarrolladas sobre la pared aparecen representadas por una línea discontinua y las depresiones entre dos de estas crestas (situadas por encima del fondo calicinal), por un contorno vacío. A. Cáliz con ocho depresiones y doce crestas. B. Cáliz con ocho depresiones y nueve crestas visibles. C. Cáliz con siete depresiones y crestas poco desarrolladas.

conocimiento bioestratigráfico y paleobiogeográfico de la región.

La recolección del material de este trabajo así como la información estratigráfica aquí mencionada ha sido realizada por Z.H., mientras que el estudio sistemático ha sido elaborado por los restantes firmantes del trabajo. El material estudiado se encuentra depositado en el Museo de Paleontología de la Universidad Nacional de Córdoba (Argentina) con los números CORD-PZ 9442 a 9482.

\section{UBICACIÓN GEOGRÁFICA Y ESTRATIGRÁFICA}

La Precordillera está ubicada en la región centrooeste de Argentina, entre $\operatorname{los} 29^{\circ}$ y $33^{\circ}$ de latitud sur y los $68^{\circ}$ y $70^{\circ}$ de longitud oeste, extendiéndose por las provincias de Mendoza, San Juan y La Rioja. Esta región, constituida por depósitos marinos de edad cámbrica a ordovícica y marino-continentales de edad carbonífera a pérmica, encierra una historia geológica muy particular, principalmente desde el punto de vista paleobiogeográfico.

En este contexto se encuentran las secuencias devónicas de la Formación Talacasto, las cuales afloran sólo en la Precordillera sanjuanina, casi sin interrupción entre $\operatorname{los} 30^{\circ}$ y $31^{\circ} 30^{\prime}$ de latitud sur, aproximadamente. Esta secuencia siliciclástica sobreyace en el sector norte y centro de la cuenca a los sedimentos silúricos de la Formación Los Espejos y en el sur a la Formación Tambolar, también silúrica. Los niveles superiores de la Formación Talacasto pasan transicionalmente a la Formación Punta Negra (Devónico) en casi toda la cuenca, salvo en el sector noreste donde son cubiertas en forma discordante por las secuencias carboníferas.

La secuencia siliciclástica de la Formación Talacasto está constituida en su base por lutitas limo-arcillosas con intercalaciones de niveles y concreciones calcáreas, las cuales disminuyen a la vez que aumenta la granulometría, pasando en la parte media a lutitas limo-arenosas intensamente bioturbadas y luego a lutitas limo-arenosas con intercalaciones de bancos de areniscas finas y algunas concreciones calcáreas. Esta secuencia ha sido interpretada por Astini (1991) como depósitos de una plataforma fangosa vinculada a la desembocadura de grandes ríos.

La Formación Talacasto es portadora de una abundante y diversificada fauna constituida principalmente por braquiópodos (como forma dominante) y en menor medida por trilobites, bivalvos, corales (tabulados y rugosos), gasterópodos, conuláridos, hiolítidos, tentaculítidos, crinoideos, ofiuroideos y ostrácodos, entre otros. Esta fauna ha sido motivo de diferentes trabajos de índole taxonómica, bioestratigráfica o paleobiogeográfica, en estos últimos años y referidos principalmente a braquiópodos (Herrera, 1991, 1993, 1995a, b; Racheboeuf y Herrera, 1994; Salas, 1995; Herrera y Racheboeuf, 1997; Herrera et al., 1998), trilobites (Edgecombe et al., 1994; Waisfeld et al., 1994; Vaccari et al., 1994) y corales tabulados (García-López y Fernández-Martínez, 1995; Fernández-Martínez et al., 1997).

La fauna de corales tabulados, al igual que ocurre con las formas de corales rugosos, ha sido hallada hasta el momento sólo en el tramo basal de la Formación Talacasto y se encuentra asociada a formas de braquiópodos típicos de la Biozona de Asociación A: Anoplia, Boucotia, Spinoplasia, Kentronetes, Sanjuanetes, entre otros (Herrera, 1991, 1995b).

La edad de la Formación Talacasto ha sido establecida, basándose en faunas de braquiópodos (Herrera, 1991, 1993, 1995b), como Lochkoviense inferior no basal a Emsiense tardío. Es necesario destacar que esta secuencia siliciclástica no alcanza la misma edad en toda la cuenca; mientras al sur (Portezuelo del Tambolar y quebrada La Cortadera) abarca desde el Lochkoviense inferior al Praguiense inferior, en la región central (quebrada río Talacasto, sección tipo) la secuencia abarca desde el Lochkoviense inferior (no basal) al 


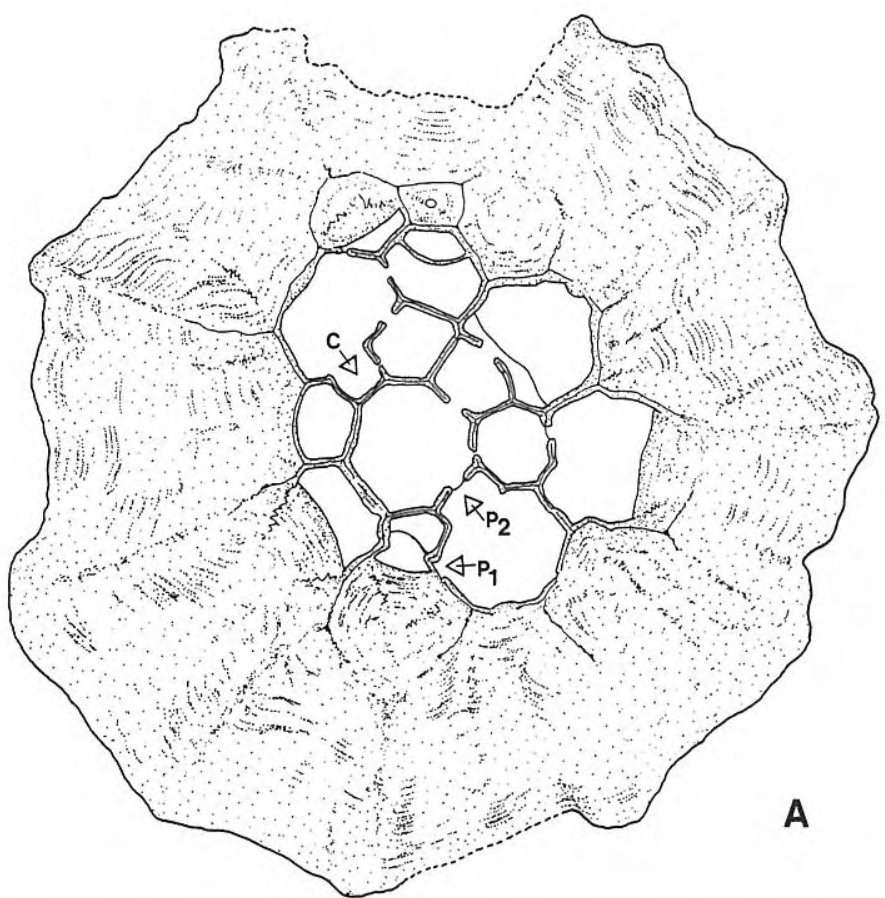

Figura 2. Parastriatopora sanjuanina n. sp. Holotipo, ejemplar CORD-PZ 9448. A. Sección transversal en la que se ha señalado la presencia de una "cella" (indicada por una C) así como varios poros angulares (P1) y murales (P2). B. Sección longitudinal. La flecha negra situada en la parte superior izquierda señala la presencia de una protuberancia vesicular en la base de la tábula. Los triángulos vacíos ubicados en la periferia de la rama indican diversas protuberancias relacionadas con el diseño de los cálices y de las paredes intercalicinales.

Praguiense superior a Emsiense, al techo de la misma, correspondiendo al Emsiense los niveles basales de la Formación Punta Negra. En las secciones más septentrionales y occidentales, la Formación Talacasto abarca una edad hasta el Emsiense tardío (Herrera et al., 1998). Por último, en el sector norte de la cuenca, el límite Silúrico-Devónico se encuentra en los niveles superiores de la Formación Los Espejos (Benedetto et al., 1992) y los niveles basales de la Formación Talacasto corresponden, según la fauna de braquiópodos, al Lochkoviense inferior no basal.

Trabajos recientes (Le Hérissé et al., 1997), sobre la base de palinomorfos estudiados en la sección de Cerro del Fuerte, asignan una edad Lochkoviense superior a la parte basal de la Formación Talacasto, a Emsiense, hacia el techo de la secuencia.

Los ejemplares descritos en este trabajo provienen de los niveles inferiores de la Formación Talacasto en las localidades de Portezuelo del Tambolar y quebrada La Cortadera (también llamada de Los Algarrobos) al sur de la cuenca, de edad Lochkoviense inferior. El material estudiado es abundante en ambas localidades, encontrándose en los niveles carbonáticos de 5 a $20 \mathrm{~cm}$ de espesor, intercalados en las lutitas de la base.

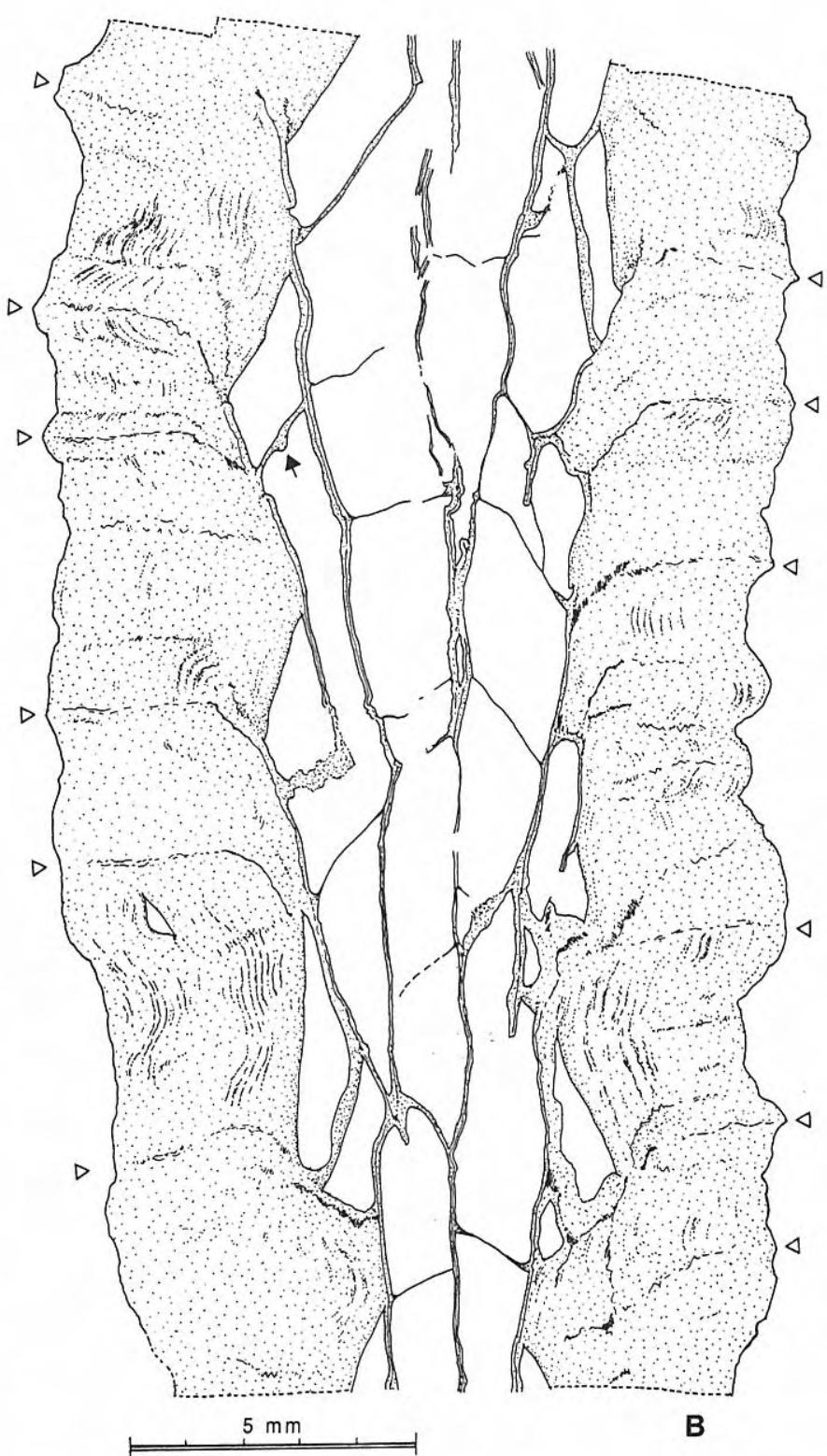

\section{SISTEMÁTICA}

CLASE ANTHOZOA Ehrenberg, 1834

SUBCLASE TABULATA Milne-Edwards y Haime, 1850

ORDEN FAVOSITIDA Wedekind, 1937

Familia Parastriatoporidae Tchudinova, 1959

Género Parastriatopora Sokolov, 1949

Especie tipo: Parastriatopora rhizoides Sokolov, 1949 del Llandovery de la Plataforma de Siberia, por designación de Sokolov (1955).

Diagnosis: Ver Lafuste et al., 1992.

Parastriatopora sanjuanina Fernández-Martínez, Plusquellec y Tourneur, n. sp.

Figs. 1-5; Láms. I, II, III 
1995 Parastriatopora cf. gigantea (Knod, 1908); GarcíaLópez y Fernández-Martínez, 178-180, Fig. 3.

1997 Parastriatopora gigantea (Knod, 1908); FernándezMartínez, Salas, Herrera, García-López y Plusquellec, 179-182.

Derivatio nominis: Relativo a la provincia de San Juan, donde ha sido hallado el material estudiado.

Holotipo: Ejemplar CORD-PZ 9448, del cual se ha realizado una lámina delgada, conteniendo una sección transversal y otra longitudinal, y una lámina LFP transversal (Figs. 2, 4A; Lám. I, figg. 1; Lám. II, figs. 1, 2; Lám. III, figs. $1,2,3)$.

Localidad tipo: Quebrada La Cortadera, también llamada de Los Algarrobos, provincia de San Juan, sur de la Precordillera central (Argentina).

Estratotipo y edad: Niveles carbonatados situados en la base de la Fm. Talacasto. Lochkoviense inferior.

Paratipos: Ejemplar CORD-PZ 9443, del cual se ha elaborado una lámina delgada que contiene tres secciones, una transversal, una longitudinal y una tangencial a la dirección de crecimiento de la rama. Ejemplar CORD-PZ 9444 en el cual se han preparado una lámina delgada que contiene una sección transversal y otra longitudinal y una lámina de tipo LFP longitudinal a la dirección de crecimiento de la rama.
Material: Treinta y ocho fragmentos de ramas. En 15 de ellos se realizaron 19 láminas delgadas que contienen 15 secciones transversales, 15 longitudinales y 4 tangenciales a la dirección de crecimiento de las ramas, así como 12 láminas de tipo LFP.

Parte de este material ( 7 ramas) es topotípico y el resto (30 ramas) procede de la localidad de Portezuelo del Tambolar. En ambos casos, todas las ramas fueron recolectadas en niveles basales de la Formación Talacasto, de edad posiblemente Lochkoviense inferior.

Adicionalmente, se han revisado seis ramas procedentes de la localidad de Tambolar y descritas como Parastriatopora cf. gigantea por García-López y Fernández-Martínez (1995), que pueden ser asignadas a la nueva especie.

\section{Diagnosis}

Especie de Parastriatopora formada por ramas cilíndricas de diámetro entre 7 y $20 \mathrm{~mm}$. Zona axial bien diferenciada, centrada, constituida por un pequeño número de coralitas de diámetro variable entre 0,7 y 3,6 $\mathrm{mm}$, separadas por paredes de espesor en torno a 0,1-0,2 $\mathrm{mm}$ en el centro y hasta $0,4 \mathrm{~mm}$ en la periferia. En las ramas juveniles, el reborde periférico está poco desarrollado y las coralitas desembocan de forma oblicua, generando cálices longitudinalmente alargados. Las ramas maduras tienen un reborde periférico bien desarrollado y compacto; las coralitas desembocan perpendicularmente a la superficie de la rama, donde muestran un contorno poligonal de entre 1,4-6 $\mathrm{mm}$ de

\section{Lámina I. Parastriapora sanjuanina n. sp.}

1 Holotipo, CORD-PZ 9448. Aspecto externo de la rama mostrando la forma poligonal de las coralitas en superficie y la ornamentación de las paredes calicinales formada por unas 12 crestas separadas por 8 depresiones especialmente marcadas en la base del cáliz. El límite entre coralitas adyacentes está subrayado por una alineación de gránulos. x5.

2 Ejemplar CORD-PZ 9461. Aspecto de una rama juvenil mostrando los cálices profundos y longitudinalmente alargados. Comparar con el ejemplar de la figura 1. x5.

3 Ejemplar CORD-PZ 9454. Aspecto de los cálices en detalle. Observar la presencia de ocho surcos desarrollados a modo de depresiones puntiformes en la base del cáliz. Esta rama contiene, en la zona media de la figura, un cáliz teratológico con un número doble de crestas y surcos (flecha blanca). x5.

4 Ejemplar CORD-PZ 9452. Detalle de los cálices mostrando la ornamentación constituida por una alternancia de crestas y surcos. Se aprecia la presencia de crestas bifurcadas que se unen en la base del cáliz, así como el desarrollo de gránulos alineados entre dos coralitas. $\mathrm{x} 5$.

5 Ejemplar CORD-PZ 9458. Aspecto externo de una rama. Observar la ornamentación formada por una alternancia de crestas, en este caso claramente bifurcadas, y por surcos. Notar la depresión puntiforme que los surcos generan en la base del cáliz. x5.
6 Ejemplar CORD-PZ 9442. Aspecto, en muestra de mano, de una rama madura poco alterada y con la ornamentación bien conservada. x1,3.

7 Ejemplar CORD-PZ 9446. Aspecto, en muestra de mano, de una rama madura profundamente alterada. Observar la desaparición ocasional de la ornamentación y la transformación de la cresta de gránulos en un surco. $\mathrm{x} 2,5$.

8 Ejemplar CORD-PZ 9444. Rama mostrando una patología consistente en un recrecimiento superficial de coralitas fuertemente deformadas, con desarrollo oblícuo y limitadas por paredes delgadas carentes de ornamentación. Comparar con la sección longitudinal de esta misma rama (Lám. II, fig. 6). x1,5.

9 Ejemplar CORD-PZ 9447. Aspecto, en muestra de mano, de una rama bifurcada. En este caso, la alteración ha atenuado la ornamentación y ha marcado más netamente la pared intercalicinal. $x 1,5$.

10 Ejemplar CORD-PZ 9443. Sección longitudinal en lámina delgada de una rama bifurcada. Observar la neta delimitación entre la zona axial y el reborde periférico y los cambios experimentados por la zona axial durante el período de bifurcación. Es evidente en esta figura la presencia de un recubrimiento interior de los elementos esqueléticos constituido por dolomita fuertemente pigmentada. $\mathrm{x} 3$. 


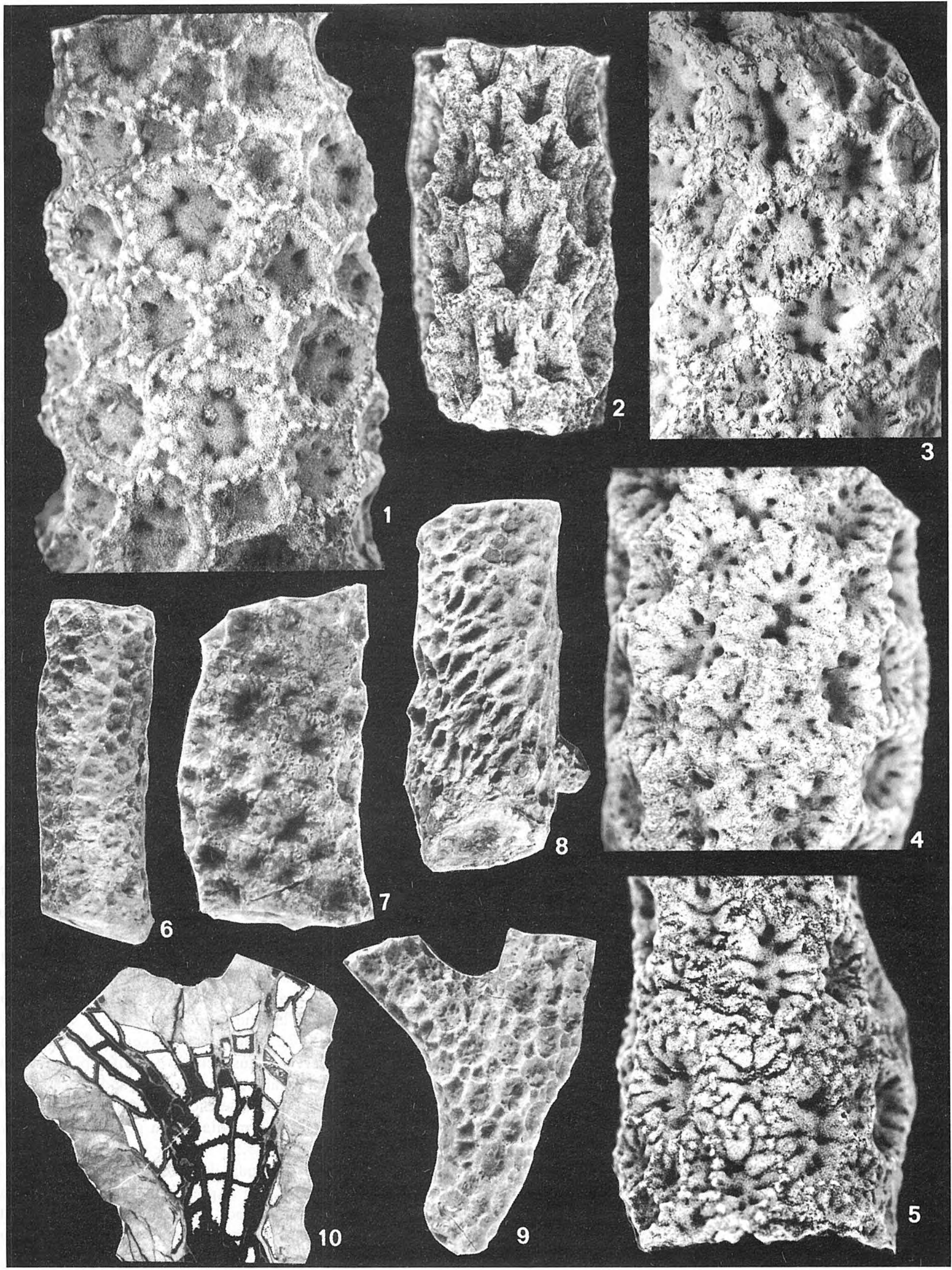

Revista Española de Paleontología, 14 (1), 1999. 
diámetro. Paredes calicinales ornamentadas con entre 812 crestas, separadas por 8 surcos que finalizan a modo de depresiones puntiformes en la base del cáliz. Poros murales y angulares. Microestructura formada por microlamelas de gran tamaño.

Species of Parastriatopora forming cylindrical branches with diameter between 7 and $20 \mathrm{~mm}$. Well differentiated axial zone composed of few corallites with diameter between 0,7 and 3,6 $\mathrm{mm}$. Wall thickness varying from 0,1-0,2 mm in the central part of branches to 0,4 $\mathrm{mm}$ in the peripheral part. Young branches with poorly developed peripheral rim and oblique incidence of corallites to the surface, creating longitudinally elongated calices. Mature branches with well developed compact peripheral rim and polygonal calices perpendicular to the surface (diameter from 1,4 to 1,6 $\mathrm{mm})$. Calicinal walls bearing $8-12$ ridges, separated by 8 furrows which create small punctiform depressions on the calicinal floors. Pores in mural and angular positions. Microstructure showing large microlamellae as usual constituant of stereoplasm.

\section{Descripción}

Debido a la importante variabilidad morfológica exhibida por los corales en general y por los representantes del género Parastriatopora en particular, la siguiente descripción no está restringida al holotipo sino que se orienta a mostrar la variabilidad presentada tanto por el conjunto del material topotípico como por el material procedente de la segunda localidad muestreada, Portezuelo del Tambolar. La figuración incluida pretende así mismo mostrar la fuerte variabilidad observada especialmente en el aspecto exterior de estas ramas, la cual puede ser debida a causas paleoecológicas pero también a los diferentes tipos de alteración reciente de las mismas.

En la descripción del material, hemos considerado oportuno incluir los datos numéricos más relevantes pero la variabilidad cuantitativa del mismo se expresa también mediante diferentes datos incluidos en dos tablas anexas. La Tabla 1 informa de las dimensiones de las ramas de todos los ejemplares que fueron estudiados en lámina delgada. La Tabla 2 contiene diversos datos cuantitativos del holotipo así como diversos estadísticos descriptivos (media, desviación típica, rango) hallados para dos conjuntos de ejemplares bien diferenciados: las ramas maduras y las juveniles.

El material estudiado está constituido por 41 fragmentos de ramas, la mayoría de los cuales se encuentran totalmente extraídos de la matriz. De ellos, ocho pueden ser definidos como pertenecientes a ramas juveniles, en el sentido de que las coralitas que las constituyen no alcanzaron un desarrollo pleno y algunos caracteres de estas ramas son, por ello, netamente diferentes de los exhibidos por los ejemplares maduros. Cuando esto ocurre, ambos tipos se describen separadamente. No se han encontrado posibles bases de colonias pero sí un fragmento que muestra el aspecto de la extremidad de una rama y cuyos rasgos se encuentran próximos a los descritos para las ramas juveniles.

\section{Morfología externa}

Ramas maduras

Las ramas maduras muestran un contorno redondeado a excepción de las regiones afectadas por una bifurcación donde adquieren un perfil ovalado. El diámetro máximo medido en los diferentes ejemplares oscila entre 9 y $20 \mathrm{~mm}$, pero la base de ramas resultantes de una bifurcación puede no sobrepasar los $7 \mathrm{~mm}$ (ver Tabla 1). El fragmento más largo de los estudiados alcanza los $40 \mathrm{~mm}$. Diez de estos

\section{Lámina II. Parastriapora sanjuanina n. sp.}

1-2 Ejemplar CORD-PZ 9448. Holotipo. 1. Sección longitudinal. Observar la neta diferenciación entre la zona axial formada por un pequeño número de coralitas y el reborde periférico bien desarrollado y compacto. x3,5. 2. Sección transversal. x3,5.

3-5 Ejemplar CORD-PZ 9442. 3. Sección longitudinal que permite apreciar el desarrollo de las coralitas en la zona axial y las transformaciones experimentadas en periferia así como la compacidad del reborde periférico. Rama madura cuya parte izquierda muestra un fino recrecimiento exterior (flecha). x2,5. 4. Sección transversal; la ornamentación granular de las paredes intercalinales aparece, en este caso, bien reproducida en la zona indicada por una flecha. x3. 5. Detalle mostrando un caso de gemación por brote lateral asociado a un poro y la presencia de una laminación de crecimiento especialmente marcada en la región derecha de la figura. $x 7$.

6-7 Ejemplar CORD-PZ 9444. Paratipo. 6. Sección longitudinal mostrando recrecimientos laterales en la superficie de la rama. x2. 7. Sección transversal; se observa un reborde periférico bien desarrollado y una zona axial pequeña, que contiene una delgada capa de coralitas subperiféricas seccionadas tangencialmente a su dirección de crecimiento. x3.

8-9 Ejemplar CORD-PZ 9443. Paratipo. 8. Sección longitudinal mostrando el aspecto de los elementos esqueléticos. x3. 9. Sección transversal mostrando un perfil irregular de la rama, provocado al seccionar límpiamente el interior de los cálices. x5,5.

10 CORD-PZ 9447. Sección longitudinal de una rama bifurcada donde se aprecia el aumento en tamaño y número de coralitas de la zona axial en la región relacionada con la bifurcación. x3.

11 CORD-PZ 9472. Sección transversal de una rama juvenil. Observar la ausencia de una diferenciación neta entre la zona axial, relativamente grande y el reborde periférico. Este último se encuentra poco desarrollado y conserva la lámina media negra aunque muestra ya cierta compacidad. $\times 5,5$.

12 CORD-PZ 9444. Detalle de la zona axial de la figura 7. Se aprecia claramente la presencia de un doble relleno diagenético formado por una capa inicial de dolomita prismática, con terminaciones euhedrales y fuertemente pigmentada y por un cristal central de calcita. $\mathrm{x} 7$. 
Lámina II

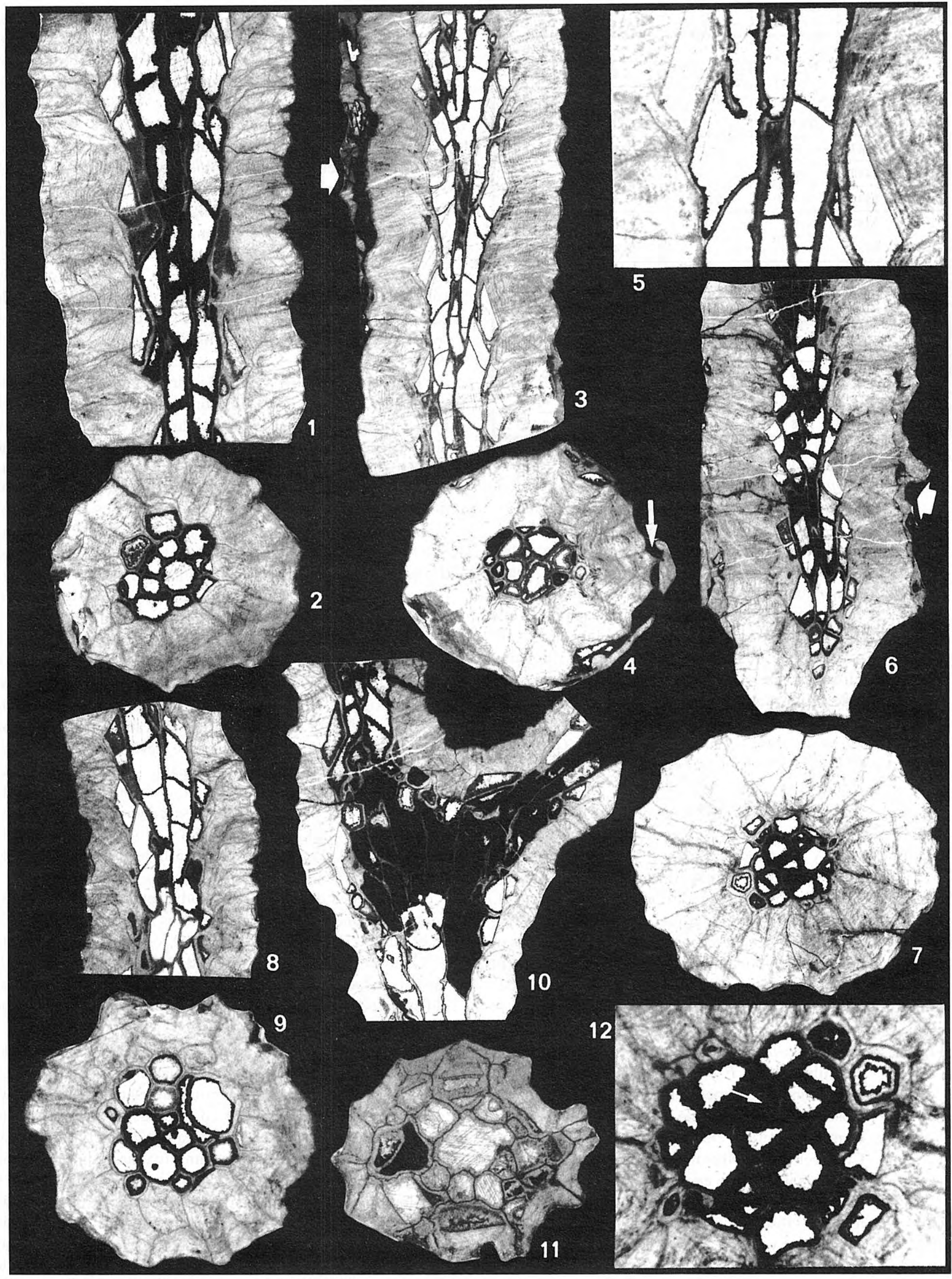

Revista Española de Paleontología, 14 (1), 1999. 


\begin{tabular}{|l|c|c|c|c|}
\hline Ejemplar & Dr max & Dr & Dza & Dza/Dr \\
\hline CORD-PZ 9442 & 17 & 16 & 6 & 0,38 \\
\hline CORD-PZ 9443 & 11 & 10,8 & 5,6 & 0,52 \\
\hline CORD-PZ 9444 & 20 & 19,6 & 7,4 & 0,38 \\
\hline CORD-PZ 9445 & $20(10)$ & 14,7 & 6,75 & 0,46 \\
\hline CORD-PZ 9447 & $13(7)$ & 8,8 & 4,2 & 0,48 \\
\hline CORD-PZ 9448 & 13 & 13 & 5 & 0,38 \\
\hline CORD-PZ 9449 & $12(10)$ & 13,8 & 9,4 & 0,68 \\
\hline CORD-PZ 9453 & 14 & 14 & 6 & 0,43 \\
\hline CORD-PZ 9457 & 14,5 & 14,5 & 7,4 & 0,51 \\
\hline CORD-PZ 9468 & $14(11)$ & 14 & 7 & 0,50 \\
\hline CORD-PZ 9471 & 11 & 10,5 & 5 & 0,48 \\
\hline CORD-PZ 9472 & 9,5 & 9,5 & 4 & 0,42 \\
\hline CORD-PZ 9474* & 7,2 & 7,2 & 5 & 0,69 \\
\hline CORD-PZ 9475* & 9 & 9 & 4 & 0,44 \\
\hline CORD-PZ 9478* & 7 & 7 & 3,2 & 0,46 \\
\hline CORD-PZ 9479* & 8 & 8 & 4 & 0,50 \\
\hline
\end{tabular}

Tabla 1. Dimensiones (en $\mathrm{mm}$ ) de las ramas de Parastriatopora sanjuanina $\mathrm{n}$. sp. Los ejemplares con asterisco han sido considerados como ramas juveniles. La tabla incluye sólo los ejemplares medidos en lámina delgada; los diámetros del resto de las ramas estudiadas se encuentran entre los aquí indicados. Dr max = diámetros máximos medidos directamente sobre las ramas. Los datos dobles se refieren a medidas tomadas antes ( $\sin$ paréntesis) y después (con paréntesis) de una bifurcación. $\mathrm{Dr}=$ diámetro de la rama en la zona donde se ha realizado la lámina delgada y donde, por tanto, puede también medirse el diámetro de la zona axial (Dza). La última columna (Dza/Dr) refleja la relación entre ambas zonas.

fragmentos se encuentran en diferentes fases de bifurcación, la cual es de tipo dicotómico y genera ramas separadas por ángulos entre 50 y $80^{\circ}$ (Lám. I, figs. 9, 10; Lám. II, fig. 10).

La superficie de las ramas maduras está ocupada por coralitas perpendiculares y de contorno poligonal (Lám. I, fig. 1), con un número de lados que oscila habitualmente entre 4 y 8 (6 lo más frecuente), aunque también existen coralitas con 9 y 10 lados. Los datos sobre su diámetro, medido sobre la superficie de las ramas y en función del número de lados, pueden ser consultados en la Tabla 2. A grandes rasgos puede indicarse que el diámetro medio de las coralitas con 4 y 5 lados oscila entre 1,4 y $5 \mathrm{~mm}$; las coralitas con 6 y 7 lados muestran diámetros medios comprendidos entre 2,2 y $5,4 \mathrm{~mm}$; las coralitas con 8 o más lados tienen tamaños que varían entre 3,6 y $6 \mathrm{~mm}$, siendo éste último el mayor diámetro medido.

La parte central de cada coralita está ocupada por el cáliz que es, en general, bastante somero y de fondo horizontal, aunque existen excepciones a este modelo. Así, y especialmente en el ejemplar tipo, algunos fondos calicinales son ligeramente convexos (Lám. I, fig. 1) mientras que en otras ramas pueden alcanzar una cierta profundidad o ser ligeramente cóncavos (Lám. I, figs. 3, 4). El contorno del cáliz se ajusta al de la coralita, siendo redondeado o alargado en función del perfil de ésta (Fig. 1). Su diámetro máximo oscila entre 1 y $3,2 \mathrm{~cm}$, pero la mayoría de ellos se encuentra entre 1,4 y $2,2 \mathrm{~cm}$.

En la superficie de la rama, la pared entre dos coralitas se encuentra bien desarrollada, con espesores medios en los diferentes ejemplares que oscilan entre 0,8 y $1,8 \mathrm{~mm}$, aunque excepcionalmente se han medido espesores mucho mayores (ver Tabla 2). Esta pared carece de poros y está ornamentada por entre 8 y 12 crestas septales continuas y de desarrollo centrípeto (Fig. 1; Lám. I, figs. 4, 5). Las crestas están habitualmente separadas por 8 surcos, muy raramente 5-7 en coralitas jóvenes, con 4 o 5 lados; estos surcos son delgados y profundos y se encuentran especialmente marcados en la zona limítrofe entre el fondo del cáliz y la pared lateral de la coralita, donde se desarrollan como pequeñas depresiones redondeadas (Fig. 1; Lám. I, figs. 1, 4). El mayor número de crestas en relación con el de surcos se consigue mediante la bifurcación de algunas de éstas (Lám. I, fig. 5). Una única excepción a este modelo ha sido apreciada: se trata de una coralita de gran tamaño $(4,2 \mathrm{~mm}$ de diámetro) en cuyo perímetro se desarrollan 16 crestas separadas por 16 surcos (Fig. 1; Lám. I, fig. 3). En varias coralitas con crestas gruesas, se ha observado la prolongación de éstas sobre la base calicinal, en la cual se unen dos de ellas (Lám. I, fig. 4). A grandes rasgos, la ornamentación cresta/surco provoca la aparición de perfiles calicinales fuertemente festoneados.

Las paredes de dos coralitas adyacentes están separadas por alineaciones de pequeños gránulos aplastados y estirados en el sentido de la pared y que son el resultado del desarrollo de la lámina media en el exterior de la rama (Lám. I, figs. 1, 4). Esta relación se observa claramente en algunas láminas delgadas con el borde externo bien conservado y en las que

Figura 3. Parastriatopora sanjuanina n. sp. Comparación de los rasgos morfológicos internos desarrollados en las ramas juveniles (A, B, E y F) y en las ramas maduras (C, D). A. Sección transversal del ejemplar CORD-PZ 9475. La alteración de la superficie externa de la rama pone en evidencia la microestructura microlamelar de esta especie. Observar la presencia de cálices profundos y el escaso desarrollo del reborde periférico. B. Sección transversal del ejemplar anterior. Observar el escaso desarrollo del reborde periférico y la desembocadura oblícua de las coralitas. C. Sección transversal del ejemplar CORD-PZ 9443. Comparar el aspecto de esta rama madura con la sección transversal figurada en A y perteneciente a una rama juvenil. D. Sección longitudinal del ejemplar CORD-PZ 9443. Comparar el aspecto de esta rama madura con la sección longitudinal figurada en B y perteneciente a una rama juvenil. Observar el diseño de los cálices y de las paredes intercalicinales marcado en la superficie de la rama (triángulos vacíos). E. Sección transversal del ejemplar juvenil CORD-PZ 9474, con un reborde periférico apenas desarrollado. F. Detalle de la sección longitudinal del ejemplar juvenil CORD-PZ 9474. Observar la presencia de protuberancias vesiculares en la parte inferior de una tábula (flecha). Símbolos como en la Fig. 2A. 

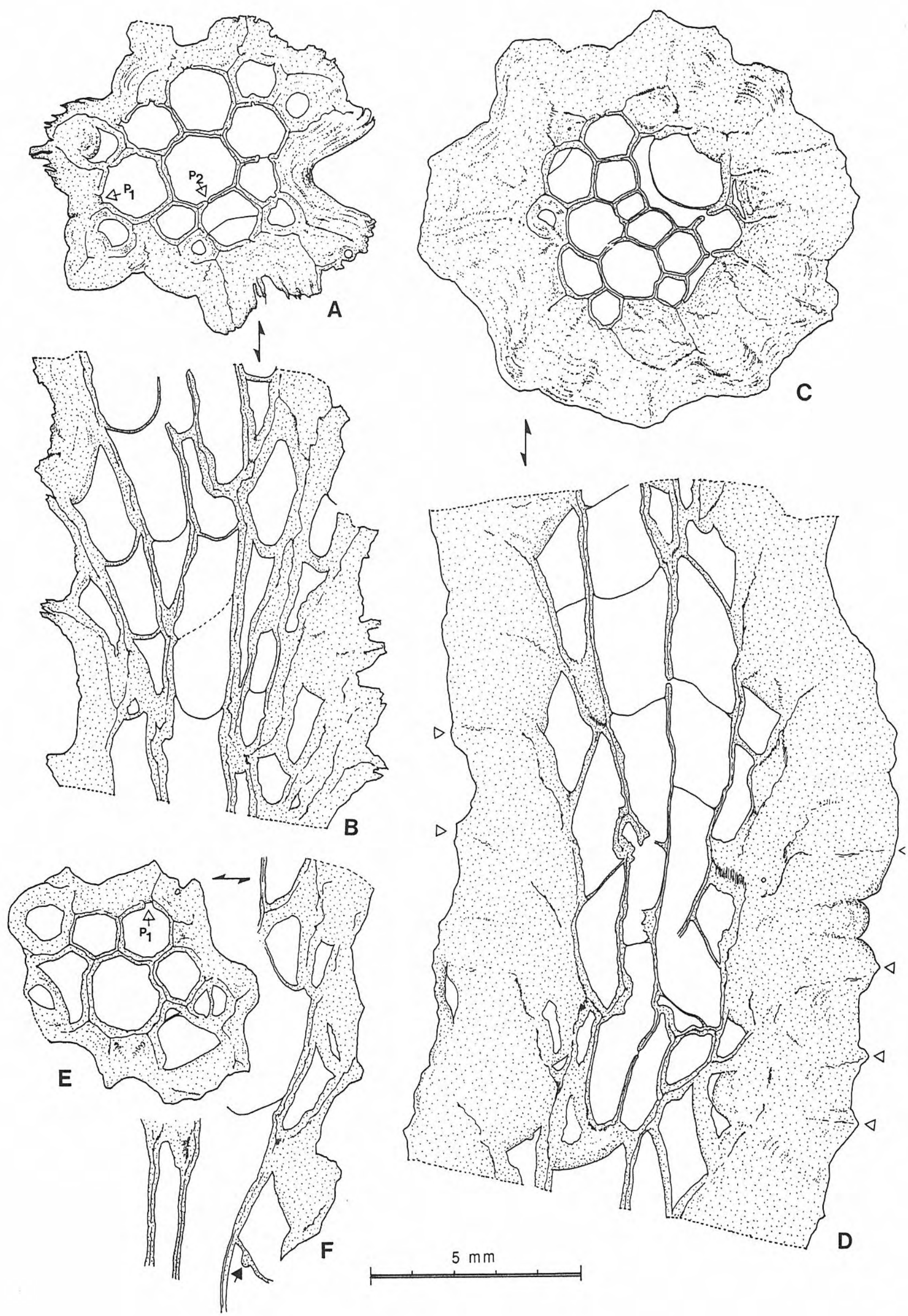


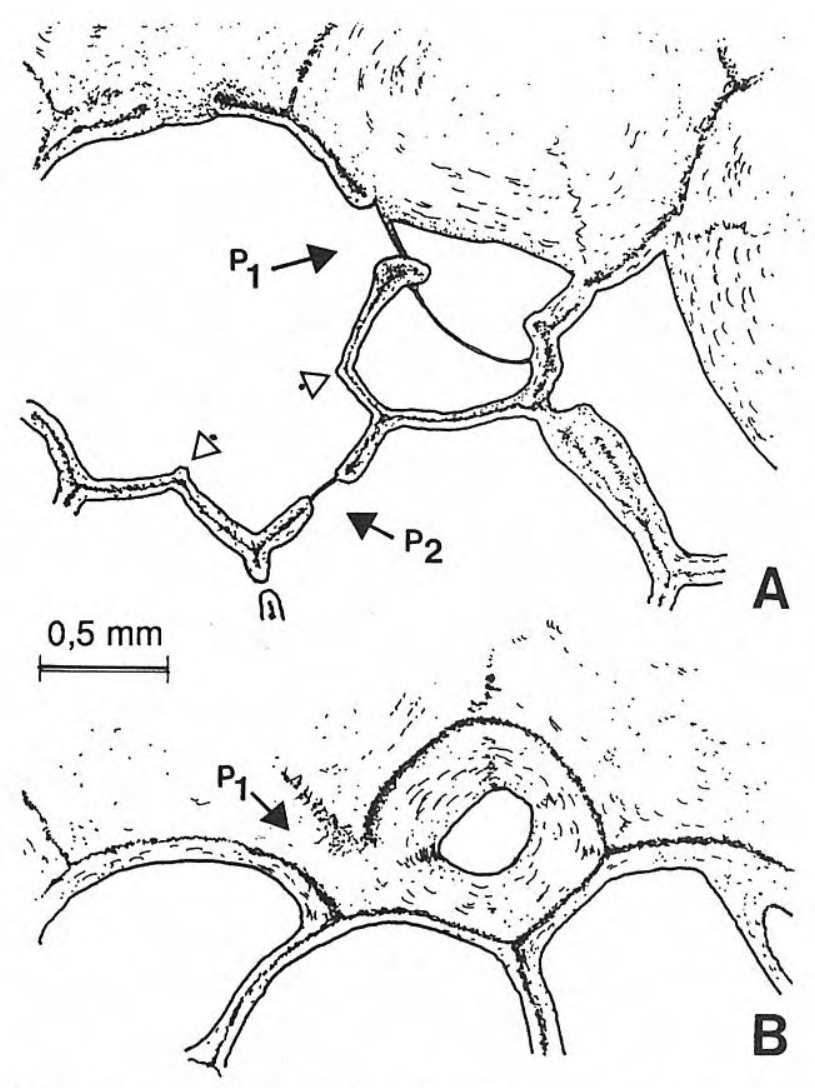

Figura 4. Parastriatopora sanjuanina n. sp. Detalle de los poros angulares (P1) en la región de contacto entre la zona axial y el reborde periférico. A. Ejemplar CORD-PZ 9448 (holotipo). Poro angular (P1) y mural (P2) obturados por diafragmas. Los triángulos vacíos señalan los límites de una "cella". B. Ejemplar CORD-PZ 9443. Interrupción de la lámina media interpretada como un poro angular (P1) obturado por el esclerénquima de la zona periférica. la lámina media integrada en la pared da paso, hacia la periferia de la rama, a una pequeña elevación (Figs. 2B, 3D; Lám. II, fig. 4; Lám. III, figs. 3, 4).

En muestra de mano, el diferente grado y tipo de alteración de la superficie externa puede generar ramas de aspecto muy diferente (comparar los ejemplares reproducidos en las figuras 6, 7 y 9 de la Lámina I). En caso de meteorización intensa, la ornamentación aparece sustituida por un surco alargado situado en posición central y flanqueado por depósitos de estereoplasma de aspecto frecuentemente laminar (Lám. I, fig. 7).

En la gran mayoría de las ramas, tanto el contorno como la ornamentación de coralitas y cálices permanece bastante constante. Sin embargo, dos ejemplares procedentes de la localidad tipo, Quebrada La Cortadera (CORD-PZ 9442 y 9444) muestran recrecimientos del esclerénquima que recubren ligeramente la pared externa original. En el ejemplar CORD-PZ 9442, el recrecimiento se desarrolla tan solo en uno de los lados, es poco compacto y se instala sobre una capa de matriz, más o menos delgada (Lám. II, figs. 3, 4). El ejemplar CORD-PZ 9444 muestra recrecimientos en una gran parte del fragmento estudiado, éstos son compactos y no se establecen completamente sobre matriz, ya que ésta sólo se encuentra en las regiones más deprimidas de la superficie original de la rama (Lám. II, fig. 6). Es interesante resaltar el hecho de que, especialmente en este último caso, el recrecimiento se traduce externamente en la presencia de patologías consistentes en coralitas de contorno irregular, muy estiradas oblicuamente, paredes muy finas y ornamentación ausente o escasamente desarrollada (Lám. I, fig. 8).

\section{Ramas juveniles}

Todas las ramas que muestran rasgos juveniles se encuentran extraídas de la matriz y son fragmentos simples, sin indicios de bifurcación. Excepto una, que tiene el contorno suavemente ovalado, el resto son cilíndricas,

\section{Lámina III. Parastriatopora sanjuanina n. sp.}

1-3 Ejemplar CORD-PZ 9448. Holotipo. 1. Aspecto de la microestructura en lámina de tipo LFP. La figura corresponde a la sección transversal de una pared situada al inicio de la zona periférica (localizada en la parte superior de la figura). En ella puede observarse la microestructura granular de la lámina media (flecha negra) flanqueada por dos capas de microlamelas con la concavidad opuesta a ambos lados de la misma. x180. 2 . Detalle de la figura 1. Observar los elementos granulares que constituyen la lámina media y la forma típicamente cupular de algunas microlamelas. x 435. 3. Detalle de la sección longitudinal mostrando el abatimiento y desembocadura de una coralita, el reborde periférico compacto y la laminación de crecimiento. Observar el efecto en periferia de la sección de un gránulo situado en la zona media de la pared intercalicinal. En la zona axial puede apreciarse una tábula cuya superficie inferior muestra una protuberancia vesicular (flecha vacía, a la derecha). $\times 7,5$.
4 Ejemplar CORD-PZ 9444, paratipo. Detalle de la sección transversal donde se aprecia el efecto producido en la periferia al seccionar un gránulo situado en la zona media de la pared intercalicinal (flecha vacía). x7,5.

5 Ejemplar CORD-PZ 9443, paratipo. Detalle de la sección longitudinal mostrando el abatimiento de las coralitas y el dibujo de los cálices y la pared intercalicinal en la periferia de la rama. $x 7$.

6-7 Ejemplar CORD-PZ 9475. 6. Detalle de la sección transversal mostrando un poro mural bien seccionado. Observar también la lámina media que se encuentra fuertemente silicificada. x57. 7. Detalle de un poro angular situado en la zona subperiférica de la sección transversal de una rama y cerrado por un diafragma cuyo límite externo aparece en continuidad con la pared engrosada (flecha vacía). Observar la presencia de un claro cristal de dolomita rodeado por calcita y la silicificación local de la lámina media. x56. 
Lámina III

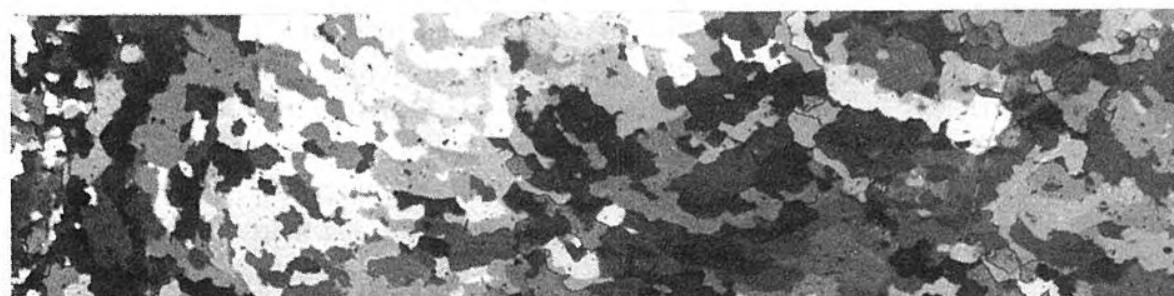

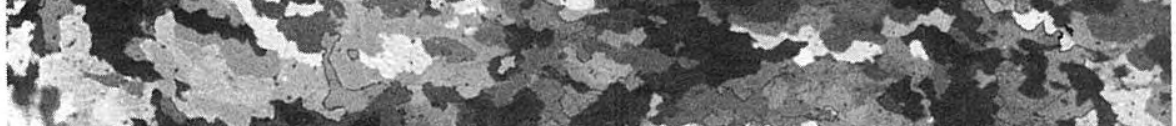

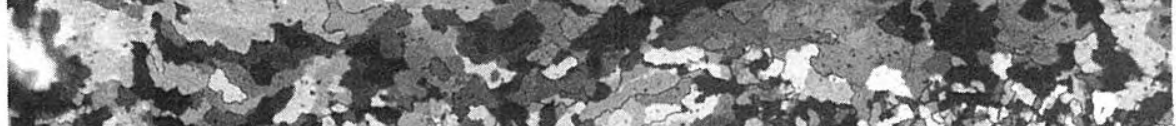

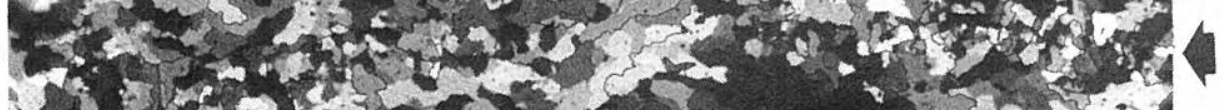

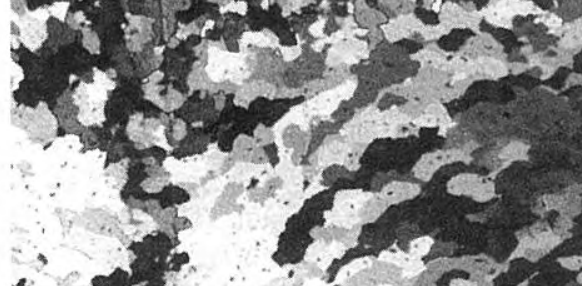

b.

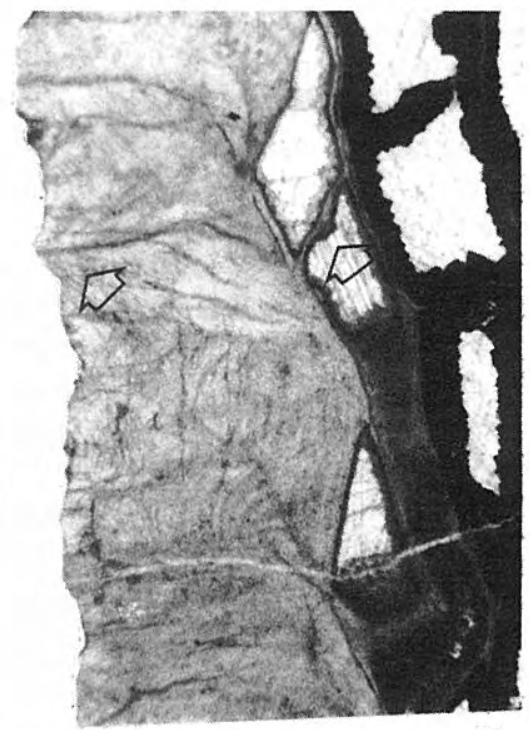

3

Anfeth -2
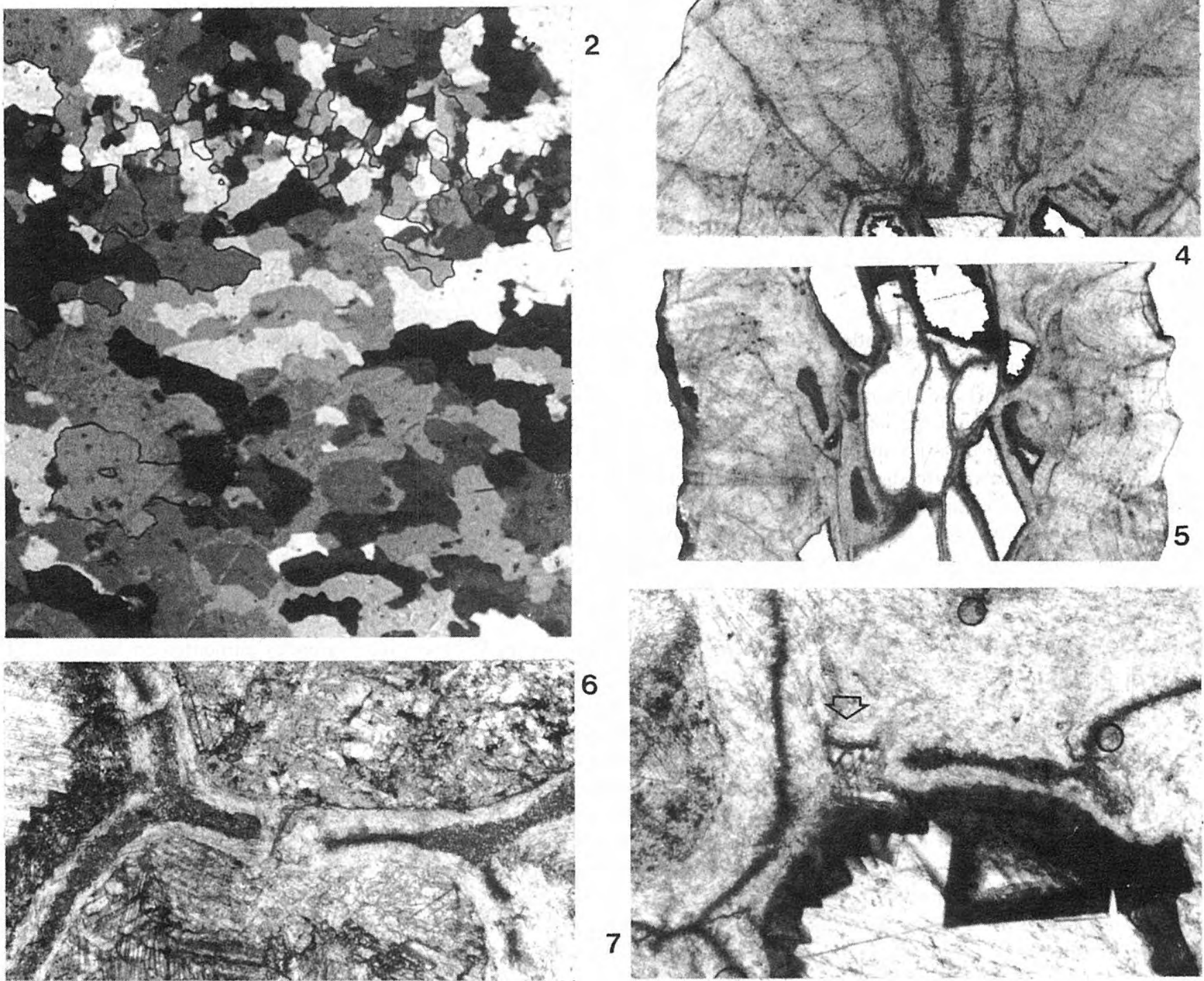

Revista Española de Paleontología, 14 (1), 1999. 
oscilando su diámetro entre 7 y $9,5 \mathrm{~mm}$. El mayor fragmento estudiado tiene una longitud de $20 \mathrm{~mm}$.

Las aberturas de las coralitas son oblicuas a la superficie y se encuentran alargadas en el sentido de crecimiento de la rama. En general, los cálices son bastante profundos, pudiendo presentar una zona aún más deprimida, incluso con forma de embudo, en su mitad inferior. En este caso, la mitad superior del cáliz desarrolla una plataforma calicinal lisa, en la que desembocan los elementos ornamentales de la pared (Lám. I, fig. 2). Este modelo presenta variaciones intercoloniales puesto que también han sido observados algunos cálices someros y de desarrollo uniforme.

Los cálices de estas ramas se encuentran mal delimitados ya que no existe una separación neta entre la plataforma calicinal y la muralla, de ahí que resulte difícil tomar medidas del grosor de la pared y del tamaño del cáliz. De forma general, puede indicarse que el espesor de la muralla oscila en torno a los $1,2 \mathrm{~mm}$, mientras que el diámetro de los cálices mayores, medido a lo largo de su longitud mayor, oscila entre 1,2 y $2,6 \mathrm{~mm}$, aunque estos límites pueden ser rebasados localmente; el diámetro pequeño de estos cálices (transversal al anterior) varía entre 1,2 y $3,6 \mathrm{~mm}$, pero habitualmente se sitúa en torno a $2,2 \mathrm{~mm}$. La pared intercalicinal muestra una ornamentación similar a la presente en las ramas maduras.

Puesto que las coralitas muestran el mismo estiramiento longitudinal que los cálices, su tamaño ha sido medido en sentido transversal a dicho estiramiento; el resultado es la presencia de coralitas menores que las presentes en las ramas maduras (comparar datos generales de la Tabla 2). Las coralitas con 4 o 5 lados muestran diámetros muy variables, entre 1,2 y $2,8 \mathrm{~mm}$, mientras que las coralitas con 6 o más lados tienen diámetros que oscilan habitualmente entre 1,4 y $3,2 \mathrm{~mm}$.

\section{Conservación del material observado en lámina delgada}

El estado de conservación del material estudiado en láminas delgadas es variable. La mayoría de las coralitas tienen sus lúmenes internamente tapizados por una capa de cemento dolomítico fibroso o prismático, con terminaciones euhedrales más o menos marcadas (Lám. III, fig. 7). Esta capa puede llegar a ocupar todo el lumen pero, más frecuentemente, éste presenta un relleno en drusa, con su parte central ocupada por uno o varios cristales de calcita.
Especialmente en las ramas procedentes de Quebrada La Cortadera este cemento se encuentra coloreado por óxidos oscuros (de Mn o Ti) y los lúmenes aparecen rellenos de calcita criptocristalina también coloreada. Es habitual la presencia de trazas de materia orgánica.

Todo el material se encuentra afectado en distinto grado por fracturas de diverso tamaño, rellenas de calcita, que atraviesan las ramas. Además, tres ejemplares procedentes de la localidad tipo tienen los elementos esqueléticos internos de la zona axial total o parcialmente fracturados, de tal forma que éstos aparecen flotando en una matriz criptocristalina muy oscura.

\section{Morfología interna}

Internamente todas las ramas estudiadas están caracterizadas por la diferenciación neta, aunque no brusca, entre una zona axial pequeña y un reborde periférico muy compacto y bien desarrollado (Fig. 2; Lám. II, figs. 1-4, 69). No obstante, las ramas con rasgos juveniles (Lám. II, fig. 11) y, en menor medida, las zonas afectadas por una bifurcación (Lám. II, fig. 10) muestran un reborde más estrecho y menos compacto. La zona axial ocupa siempre una posición central en la sección de cada rama y la relación entre el diámetro de la zona axial y el diámetro de la rama varía entre 0,38 y 0,68 (Tabla 1 ).

El reborde periférico es continuo, simétrico y muy compacto (Figs. 2, 3C-D; Lám. I, figs. 1 y 7, entre otras). Su desarrollo está ocasionado por la horizontalización de las coralitas y, muy especialmente, por el intenso engrosamiento experimentado por la pared y las tábulas (Figs. 2, 3C-D; Lám. II, fig. 1, Lám. III, fig. 5). En las ramas maduras, la fuerte compacidad generada por este fenómeno junto a la invisibilidad de la línea negra generan una zona periférica en la que no se aprecian individualmente los diferentes caracteres esqueléticos. En su lugar, se observan variaciones en el aspecto general del reborde que se corresponden básicamente con diversos cambios experimentados por los elementos microestructurales (Lám. II, figs. 3, 4); (ver apartado sobre Estructura y microestructura de la pared y de las tábulas).

En las ramas con rasgos juveniles (Fig. 3A-B, E-F; Lám. II, fig. 11), la zona más externa se corresponde con el inicio del reborde periférico de los ejemplares maduros y muestra, por tanto, los rasgos que serán descritos para éstos en la zona

Figura 5. Parastriatopora sanjuanina n. sp. Microestruc-tura de la muralla observada a grandes aumentos en láminas LFP (dibujos a cámara clara). Con cada figura se ha incluido un esquema de la localización de la zona representada. El triángulo vacío señala la ubicación de la lámina media. A. Ejemplar CORD-PZ 9444. Sección longitudinal, zona axial. Lámina media granular y fibroides con disposición tectiforme. B. Ejemplar CORD-PZ 9444. Sección longitudinal, contacto entre la zona axial y la periférica. Presencia de elementos transversales algo inclinados (flecha en la parte superior izquierda) entre los gránulos de la lámina media y de fibroides tectiformes; espesamiento asimétrico de la pared. C. Ejemplar CORD-PZ 9444. Sección longitudinal, zona periférica externa. Fibrización de la lámina media. D. Ejemplar CORD-PZ 9453, sección transversal, contacto entre la zona axial y la periférica. Elementos transversales ortogonales a la lámina media; observar la curvatura opuesta de las microlamelas a ambos lados de la misma. E. Ejemplar CORD-PAL 9471, sección transversal, zona periférica. Esclerénquima microlamelar. F. Ejemplar CORD-PAL 9457, sección transversal, zona periférica. Esclerénquima microlamelar. Las figuras A, B, D, E y F están a la misma escala. La figura C tiene una escala diferente y la localización indicada no es la real sino una equivalente. Todos los esquemas de localización están a la misma escala, representada por 0,5 $\mathrm{mm}$. 

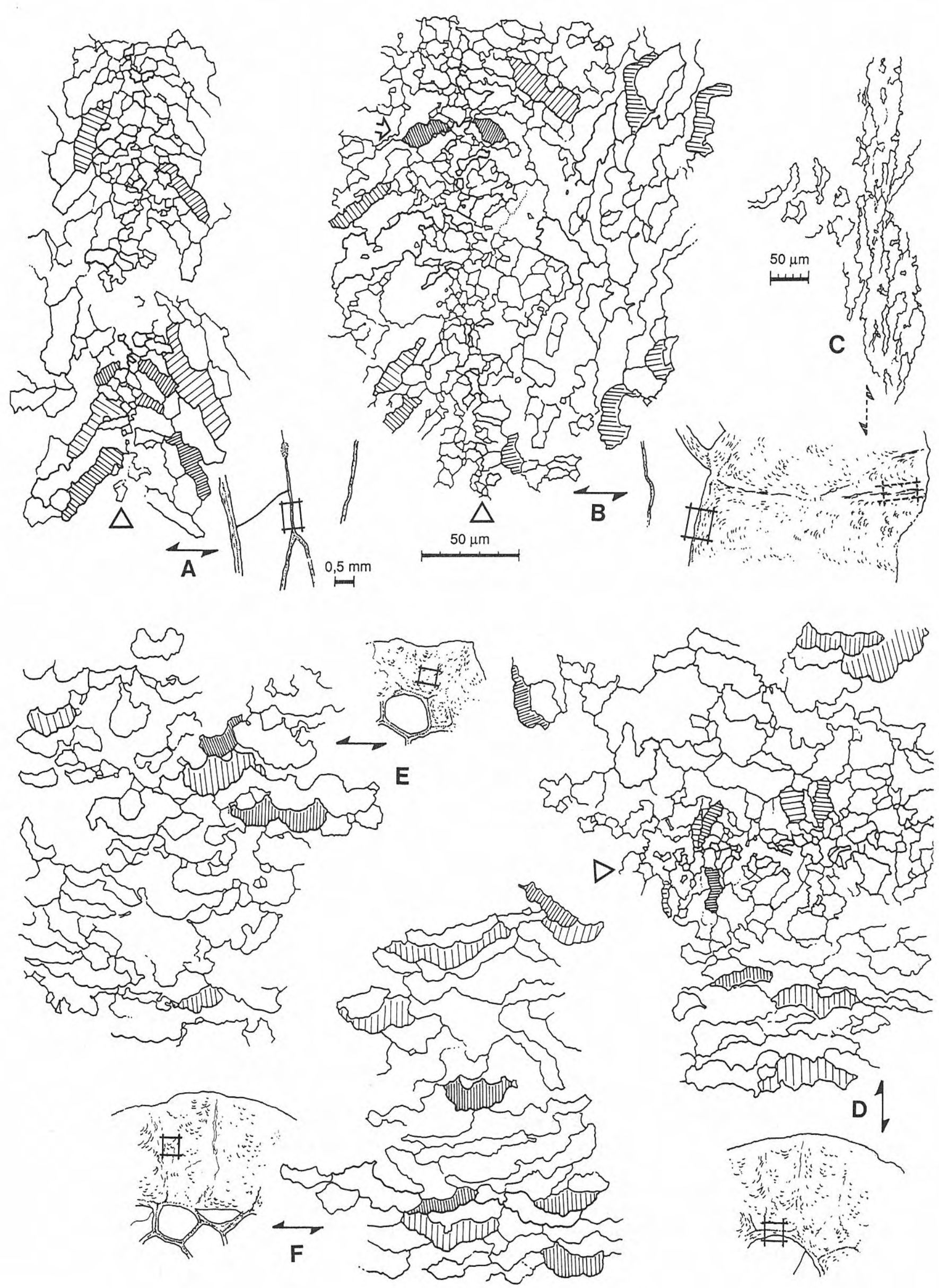
subperiférica: tábulas sólo ligeramente espesadas y con una marcada inclinación, que se traduce, externamente, en la presencia de cálices con bases cóncavas.

En los ejemplares menos erosionados, y especialmente en aquellas ramas que han sido seccionadas junto con la matriz en la cual se encontraron inmersas, la parte externa del reborde periférico dibuja las secciones de los cálices y de los elementos ornamentales que aparecen en ellos: crestas, surcos y gránulos, resultantes, éstos últimos, de la expansión periférica de la lámina media (Figs. 2B, 3D; Lám. II, fig. 4; Lám. III, figs. 4, 5).

\section{Coralitas}

En las ramas maduras, la zona axial de los cortes transversales está ocupada por entre 7 y 14 coralitas delimitadas por una muralla fina (Figs. 2A, 3C; Lám. II, figs. 2, 4, 7, 9). En su región más central, las coralitas están seccionadas perpendicularmente a su dirección de crecimiento (sección transversal) y muestran contornos poligonales más o menos irregulares, con un número de lados que oscila entre 4 y 8 (Figs. 2A, 3C; Lám. II, fig. 12).

En el caso de las ramas jóvenes, la diferencia entre la zona axial y el reborde periférico se encuentra menos marcada (Figs. 3A, 3E; Lám. II, fig. 11). La zona axial aparece constituida por un número menor de coralitas (entre 4 y 8), seccionadas transversalmente y de tamaño muy desigual. Su contorno es poligonal pero están frecuentemente delimitadas por una pared ligeramente engrosada, que genera lúmenes algo redondeados.

En ambos casos, entre la zona axial y el reborde periférico se desarrolla una corona de coralitas de gran tamaño que, por encontrarse en una fase de abatimiento lateral, son seccionadas oblicuamente a su dirección de crecimiento, por lo que su límite más externo está frecuentemente constituido por una tábula (Figs. 2A, 3C, E; Lám. II, figs. 7 y 12). Entre ellas aparecen también algunas coralitas más pequeñas, de 4 lados, seccionadas perpendicularmente a su dirección de crecimiento. En esta zona subperiférica, la pared puede mostrar un engrosamiento más acentuado y las secciones observadas son indicativas de tábulas algo más gruesas y en ocasiones muy cóncavas.

El diámetro de las coralitas (por definición, considerado de lámina media a lámina media) ha sido medido en distintos estadios de crecimiento, evaluados en función del número de lados de las coralitas y puede consultarse en la Tabla 2. En ella, puede observarse que las coralitas jóvenes, con 4 o 5 lados, tienen diámetros que oscilan entre 0,65 y 1,8 mm. Los diámetros de las coralitas mayores, con 6-7 lados, varían generalmente entre 1 y $2,7 \mathrm{~mm}$. Las coralitas cuyo contorno está formado por 8 o más lados muestran diámetros entre 1,6 y 3,6 mm. A pesar de esta importante variación, las colonias estudiadas mantienen cierta constancia en el tamaño de las coralitas medidas en función del número de lados, a excepción del ejemplar CORD-PZ 9468 (seccionado en las proximidades de una bifurcación), el cual muestra coralitas con diámetros ligeramente mayores. Por el contrario, las coralitas de las ramas jóvenes tienen tamaños que encajan bien dentro de la variabilidad citada.

En sección longitudinal, la zona axial está ocupada por entre 3 y 5 coralitas, seccionadas, al menos temporalmente, de forma paralela a su dirección de desarrollo (Figs. 2B, 3B, D; Lám. I, fig. 10; Lám. II, figs. 1, 3, 6, 8 y 10). En estos cortes, se observan varias figuras de generación de nuevas coralitas, que acontece mediante brote lateral asociado a un gran poro basal (Lám. II, figs. 3, 5). En sección transversal, la gemación por brote lateral aparece bajo la forma de coralitas de gran tamaño con uno de sus lados desarrollado en forma de cuadrado abierto (cella) (Fig. 2A; Lám. II, fig. 12).

Tras el nacimiento de cada coralita, se produce un aumento progresivo de su tamaño, coincidente con un recorrido recto o ligeramente inclinado hacia la periferia. En las ramas maduras, el límite entre la zona axial y el reborde periférico está marcado por la curvatura de las coralitas, que acontece de forma brusca y sitúa los cálices en posición perpendicular a los límites de la rama (Figs. 2B, 3D; Lám. II, fig. 1; Lám. III, fig. 3). En las ramas definidas como juveniles, la curvatura plena no llega a producirse y las coralitas desembocan oblicuamente a la superficie de la rama, experimentando en esta zona un engrosamiento de sus elementos estructurales menos marcado que el apreciado en las ramas maduras.

\section{Pared}

En la zona axial, la pared es delgada y sólo de forma local muestra un cierto engrosamiento hacia la periferia (Lám. II, figs. 5, 12). Su espesor varía generalmente entre 0,07 y $0,25 \mathrm{~mm}$, aunque algunos ejemplares (CORD-PZ 9468, sección realizada en las proximidades de una bifurcación) muestran espesores puntuales de hasta 0,40 $\mathrm{mm}$, habitualmente localizados en las proximidades de la zona periférica. En esta zona, el desarrollo de la pared es recto, con ondulaciones sólo en zonas de contacto con otras coralitas. Hacia la zona periférica, la pared muestra un fuerte engrosamiento que, por lo general, acontece de forma brutal en las proximidades del abatimiento de las coralitas (Figs. 2, 3C-D. Lám. II, cualquier sección).

Para una descripción detallada de la pared tanto en lámina delgada como en láminas LFP puede consultarse el apartado relativo a "Estructura y microestructura de la pared y las tábulas".

\section{Poros}

Diversas observaciones permiten detectar la presencia de poros tanto murales (P2) como angulares (P1). En la zona axial, han sido reconocidos varios poros murales situados en puntos aproximadamente centrales de la pared y que pueden o no estar cerrados por un diafragma (Figs. 2A, 3A, 4A; Lám. III, fig. 6). Cuando existe, éste es lateral, completo y delgado aunque, en ocasiones, se encuentra reforzado lateralmente por una capa de esclerénquima. Ningún poro angular claro ha sido observado en la zona axial, pero el ejemplar CORD-PZ 9468 muestra una región donde el recorrido y desaparición de la lámina media permiten sospechar la existencia de un poro angular completamente cerrado por un espeso tapón de esclerénquima.

En la zona limítrofe entre la región axial y el reborde periférico, se han reconocido claramente numerosos poros tanto murales (centrados o en posición lateral) como angulares (Figs. 2A, 3A, 4A, B. Lám. III, fig. 7). La mayoría 


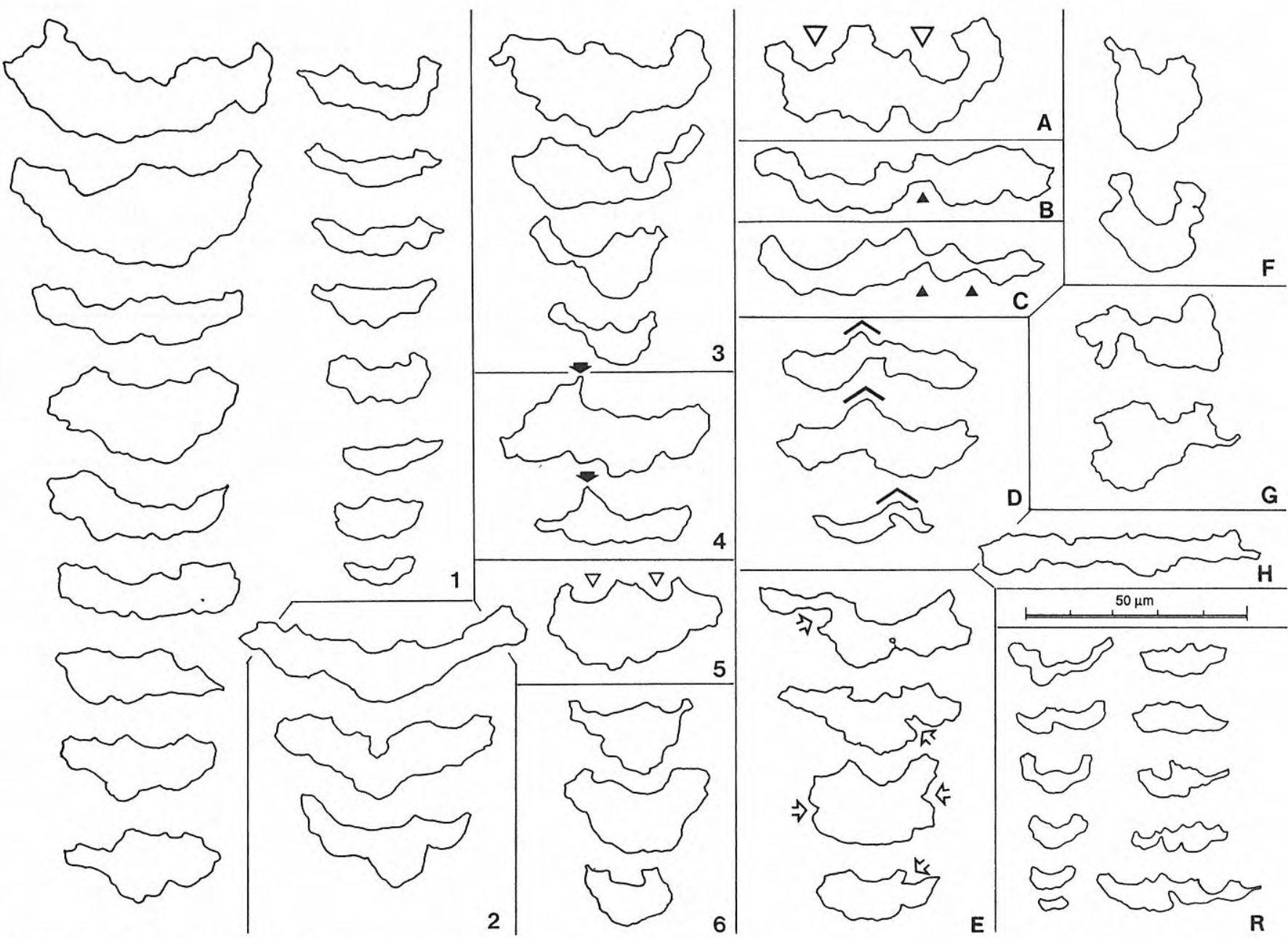

Figura 6. Morfología de los elementos microestructurales del estereoplasma de Parastriatopora sanjuanina n. sp. A modo de comparación se han figurado a la misma escala las microlamelas de Parastriatopora rhizoides Sokolov (R). 1-6. Morfología de los elementos microestructurales considerados como biocristales unitarios del tipo (gran) microlamela. 1. Elementos estándar: convexidad proximal más marcada que la concavidad distal; ausencia de una constricción mucho menor que el espesor máximo; espesor máximo a menudo próximo a la altura del elemento y localizado en la región axial; cupulación desarrollada en las dos caras; tamaño muy variable. Muy frecuente. 2. Elementos más simétricos y más netamente cóncavo-convexos que los precedentes. 3. Elementos asimétricos, con el espesor máximo no axial. Frecuente. 4. Elementos cuya cara distal posee una "punta" subaxial neta pero carece de constricción marcada en la cara proximal. 5. Elementos con 2 o 3 fuertes indentaciones sobre la cara distal. 6. Elementos "rechonchos", es decir, que presentan un espesor importante con relación a la longitud. Bastante frecuentes. A-H. Morfología de los elementos microestructurales considerados como no repesentantivos por corresponder a la fusión de dos o varias microlamelas (A-E), a secciones mal orientadas (F-G) o a formas aberrantes (H). Han sido agrupados en ocho categorías en función de su morfología. A. Elementos con dos o más curvaturas principales de aproximadamente la misma talla y de las cuales una tiene una longitud igual o superior a $30 \mu \mathrm{m}$; constricción axial variable. B. Elementos que presentan una constricción axial o subaxial bien marcada (es decir, sensiblemente inferior al espesor máximo), siendo uno de los lados mayor o igual a $30 \mu \mathrm{m}$. C. Elementos que presentan varias constricciones importantes. D. Elementos que presentan una constricción axial inferior al espesor máximo y un perfil global tectiforme. Frecuente. E. Elementos que presentan uno o dos ángulos entrantes en los lados. Frecuente. Este aspecto evoca el de las microlamelas "en tenaza" ("en tenaille") descritas en Calceola por Lafuste (1983). F. Elementos con cara proximal muy convexa y altura próxima a la longitud. G. Elementos sin forma definida, de tamaño mayor o igual a $30 \mu \mathrm{m}$ y, a menudo, de espesor importante. H. Elementos aislados entre microlamelas y que presentan una morfología "lameloide" (longitud superior a $50 \mu \mathrm{m}$, espesor débil a medio).

de los poros situados en esta zona se encuentran lateral o totalmente cerrados por gruesos depósitos de estereoplasma. En el caso de cierres laterales, es habitual la presencia de un diafragma en forma de delgada línea más oscura.
Excepto en los casos de poros completamente taponados, la muralla muestra, a ambos lados de los mismos, terminaciones rectilíneas, redondeadas o ligeramente engrosadas pero siempre suaves y sin trazas de rebordes porales. 


\begin{tabular}{|c|c|c|c|c|c|c|c|c|c|c|}
\hline EJEMPLAR & Variable & Dcza (4-5) & Dcza (6-7) & Dcza (8) & $\operatorname{Dcp}(4-5)$ & $\operatorname{Dcp}(6-7)$ & Dcp (8) & Emza & Emp & Dsttab \\
\hline $\begin{array}{l}\text { Holotipo } \\
\text { C-PZ } 9448\end{array}$ & $\begin{array}{c}X(n) \\
\text { Rango }\end{array}$ & $\begin{array}{l}1,47(3) \\
1,4-1,6\end{array}$ & $\begin{array}{l}1,6(4) \\
1,3-1,9\end{array}$ & $\begin{array}{l}2,05(3) \\
1,85-2,4\end{array}$ & $\begin{array}{c}2,8(9) \\
2-3,6\end{array}$ & $\begin{array}{c}4,24(11) \\
3,4-5\end{array}$ & $\begin{array}{l}5,27(3) \\
4,8-5,8\end{array}$ & $\begin{array}{c}0,12(18) \\
0,07-0,2\end{array}$ & $\begin{array}{c}1,67(20) \\
0,8-2,8\end{array}$ & $\begin{array}{l}3,37(9) \\
1,1-4,8\end{array}$ \\
\hline $\begin{array}{l}\text { Totales } \\
\text { maduras }\end{array}$ & $\begin{array}{c}X(n) \\
\text { Dest (N) } \\
\text { Rango }\end{array}$ & $\begin{array}{c}1,21(46) \\
0,24(10) \\
0,65-1,8\end{array}$ & $\begin{array}{c}1,7(40) \\
0,33(9) \\
1-2,7\end{array}$ & $\begin{array}{c}2,37(20) \\
0,46(9) \\
1,6-3,6\end{array}$ & $\begin{array}{c}2,73(107) \\
0,45(16) \\
1,4-5\end{array}$ & $\begin{array}{c}3,91(113) \\
0,50(18) \\
2,2-5,4\end{array}$ & $\begin{array}{c}4,67(46) \\
0,47(15) \\
3,6-6\end{array}$ & $\begin{array}{c}0,17(149) \\
0,05(11) \\
0,07-0,4\end{array}$ & $\begin{array}{c}1,49(40) \\
0,22(8) \\
0,8-2,8\end{array}$ & $\begin{array}{c}2,51(133) \\
0,50(10) \\
0,5-6,2\end{array}$ \\
\hline $\begin{array}{c}\text { Totales } \\
\text { juveniles }\end{array}$ & $\begin{array}{c}X(n) \\
\text { Dest (N) } \\
\text { Rango }\end{array}$ & $\begin{array}{l}1,15(13) \\
0,15(5) \\
0,85-1,5\end{array}$ & $\begin{array}{c}1,5(20) \\
0,11(5) \\
1,3-1,9\end{array}$ & $\begin{array}{l}2,43(6) \\
0,19(3) \\
2,3-2,8\end{array}$ & $\begin{array}{c}1,92(12) \\
0,40(5) \\
1,2-2,8\end{array}$ & $\begin{array}{l}2,4(30) \\
0,19(5) \\
1,4-3,2\end{array}$ & $\begin{array}{l}3,01(7) \\
0,47(4) \\
2,2-3,6\end{array}$ & $\begin{array}{c}0,21(52) \\
0,05(5) \\
0,1-0,5\end{array}$ & $\begin{array}{l}- \\
- \\
-\end{array}$ & $\begin{array}{c}2,85(28) \\
0,69(5) \\
1,1-4,5\end{array}$ \\
\hline
\end{tabular}

Tabla 2. Datos cuantitativos de Parastriatopora sanjuanina $\mathrm{n}$. sp. (en $\mathrm{mm}$ ) incluyendo el holotipo y datos estadísticos descriptivos diferenciados para las ramas maduras y las juveniles. Dcza = diámetro de las coralitas en la zona axial, en función del número de lados $(4-5,6-7,8)$. Dcp = diámetro de las coralitas en periferia, también en función del número de lados. Emza = espesor de la muralla en la zona axial. Emp = espesor de la muralla en periferia. Dsttab = distancia entre tábulas. La toma de medidas se realizó sobre dibujos a cámara clara; las dimensiones relativas a la zona axial (Dcza, Emza y Dsttab) fueron realizadas a partir de láminas delgadas mientras que las referidas a la periferia de la rama (Dcp y Emp) fueron tomadas sobre dibujos de la superficie de éstas. En cada caso se indica la media (X), seguida del número de medidas realizadas para su obtención (n) y el rango observado. Para los conjuntos de ramas maduras y juveniles se incluye también la desviación típica (Dest), calculada para cada variable a partir de los valores medios de cada ejemplar; $(\mathrm{N})$ expresa el número de ejemplares que han intervenido en el cálculo de la desviación típica. Como puede observarse, la principal diferencia entre los dos conjuntos diferenciados se encuentra en el tamaño de las coralitas en el exterior de la rama; debido a que las coralitas de las ramas juveniles muestran un marcado estiramiento longitudinal, las medidas realizadas corresponden en este caso al diámetro menor de las coralitas, transversal al crecimiento de la rama.

En las láminas estudiadas, no existen secciones tangenciales de paredes con poros cuya medida sea totalmente fiable. Los ejemplares observados en este tipo de sección están situados en el centro de las caras, son redondeados o longitudinalmente alargados y sus diámetros oscilan entre 0,17 y $0,20 \mathrm{~mm}$. Los poros medidos en sección transversal tienen dimensiones que oscilan generalmente entre 0,1 y $0,25 \mathrm{~mm}$. No obstante, se han medido hasta 12 ejemplares con un diámetro mayor (entre 0,3 y $0,4 \mathrm{~mm}$, ocasionalmente hasta $0,6 \mathrm{~mm}$ ) que, en la mayoría de los casos, corresponden a poros situados en la periferia de la zona axial o, especialmente los de mayor tamaño, a poros relacionados con la generación de nuevas coralitas (Lám. II, fig. 5).

\section{Tábulas}

Tanto la disposición como la separación entre las tábulas muestran una variación en diferentes regiones de la zona axial (Figs. 2A, 3B, D; Lám. I, fig. 10; Lám. II, figs. 1, 3, 6). En el centro, donde las coralitas tienen un desarrollo rectilíneo, las tábulas son delgadas $(0,07-0,1 \mathrm{~mm})$, se encuentran bastante espaciadas y son rectas, ligeramente cóncavas o convexas; horizontales o suavemente inclinadas hacia el exterior de la rama. En las proximidades del reborde periférico, coincidiendo con el inicio de la curvatura de las coralitas, las tábulas son progresivamente más gruesas (entre 0,1 y $0,3 \mathrm{~mm}$ ) y suelen ser rectas o cóncavas, pero tienen marcadas trayectorias inclinadas en el sentido de dicha curvatura (Lám. I, fig. 10; Lám. II fig. 3, entre otras). La presencia de tábulas incompletas (tabellae) es extremadamente rara y solo ha sido apreciada en el ejemplar CORD-PZ 9442.

En la zona periférica, el espesamiento de las tábulas se produce por adición de estereoplasma secundario, de tal manera que las tábulas engrosadas están constituidas por una línea negra sobre la cual se deposita una capa de estereoplasma, generalmente en continuidad con el de la pared (Lám. III, figs. 3, 5).

En varios ejemplares, tanto juveniles como maduros, se han observado tábulas cuya parte inferior, habitualmente rectilínea, muestra el desarrollo de una depresión con forma de vesícula, que es completamente rellenada por el estereoplasma que engrosa la tábula (Fig. 2B; Lám. III, fig. 3). A pesar de las escasas observaciones realizadas, no puede descartarse que se trate de un elemento generalizado en las muestras pero que, por su ubicación local en la superficie de la tábula, sólo sea seccionado de forma ocasional. Se desconoce el posible significado de esta estructura.

En las zonas axial y subperiférica, la distancia entre dos tábulas consecutivas es muy variable y oscila entre 0,5 y 6,2 $\mathrm{mm}$ de separación (Tabla 2). A grandes rasgos se observa una tendencia al acercamiento de las tábulas situadas hacia la periferia de las ramas (Lám. II, fig. 3) pero el fuerte espesamiento experimentado por éstas impide realizar medidas comprobatorias. 
Elementos septales

En las secciones estudiadas, no se han observado evidencias de la presencia de espinas septales o escámulas, aunque en el límite entre la muralla y algunas tábulas se desarrolla un engrosamiento de la primera, morfológicamente similar a una espina y que puede ser confundido con éstas. Por tanto, los elementos septales se restringen a las crestas que ornamentan los cálices.

Estructura y microestructura de la pared y de las tábulas Láminas de espesor petrográfico $(30 \mu \mathrm{m})$

En láminas de espesor petrográfico $(30 \mu \mathrm{m})$, la pared entre dos coralitas de la zona axial aparece constituida por una lámina media oscura, bordeada por estereoplasma claro y estrecho. La lámina media es básicamente recta y continua aunque, principalmente en las secciones longitudinales, se observan algunas interrupciones. Estas pueden ser debidas a la presencia de poros totalmente cerrados ( $y$, por tanto, apenas visibles) o bien estar relacionadas con la silicificación de esta estructura, en ocasiones perfectamente identificable y que conlleva un aumento en el espesor y un cambio en la apariencia de la lámina media (Lám. III, fig. 6).

En las ramas maduras, la lámina media oscura desaparece en la periferia (Fig. 3; Lám. III, figs. 3, 4 y 5), siendo reemplazada por una estrecha banda clara de contorno irregular que refleja un fenómeno de fibrización de esta estructura (ver apartado siguiente). Por el contrario, en las ramas juveniles, la lámina media no desaparece ni varía su aspecto sino que se desarrolla de forma habitual hasta el final de la misma (Fig. 3; Lám. II, fig. 11).

El estereoplasma periférico se encuentra fuertemente engrosado, por lo que en él apenas se diferencian los diferentes elementos esqueléticos. En su lugar aparecen líneas oscuras con desarrollo en zig zag irregular, que corresponden a distintas orientaciones de paquetes de biocristales, cada uno de los cuales espesa una pared o una tábula. En esta zona aparecen también clivajes de calcita, localmente muy desarrollados y que dificultan la lectura de las distintas estructuras.

Especialmente en algunas secciones longitudinales, la zona periférica muestra la presencia clara en pared y tábulas de estrías de crecimiento que se manifiestan como una alternancia regular de zonas claras y oscuras, separadas por intervalos de aproximadamente 0,1-0,15 mm (Fig. 2; Lám. II, figs. 1, 5).

\section{Láminas LFP}

Las láminas ultradelgadas con caras pulidas (LFP) permiten observar los contornos de los cristales que constituyen la pared y las tábulas. En los ejemplares estudiados, la microestructura original se encuentra parcialmente modificada por fenómenos de recristalización que, o bien afectan especialmente al estereoplasma o bien son más fácilmente identificables en esta parte del esqueleto. A continuación se describe y figura la organización y morfología de los cristales del esqueleto y se discute su naturaleza, original o diagenética.

\section{Lámina media}

Tanto en la zona axial como en el borde de la zona
RELACION L/H

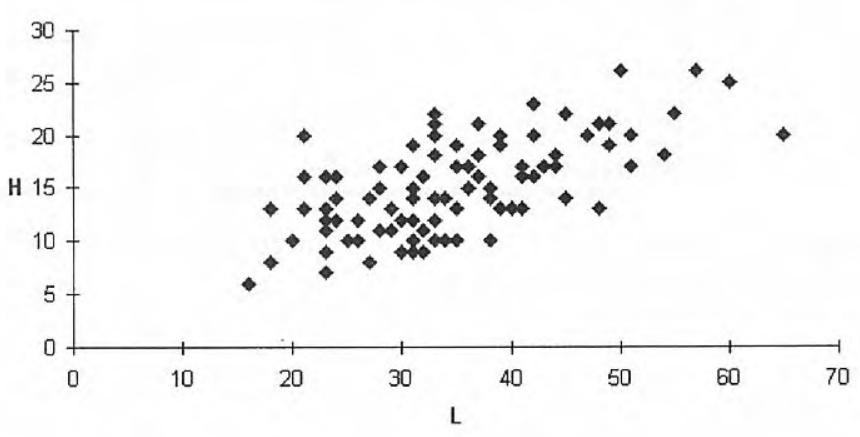

RELACION L/E

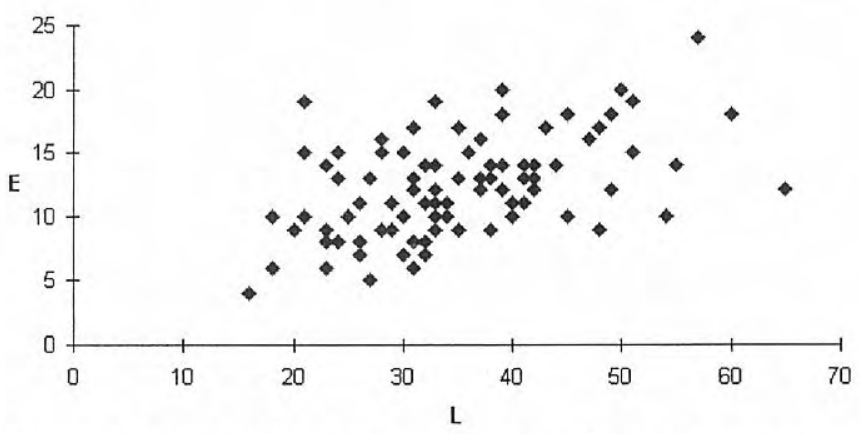

Figura 7. Arriba: Diagrama de correlación entre la longitud (L) de las microlamelas de la serie 1 y la altura (H) de éstas. El índice de correlación es de 0,65. Abajo: Diagrama de correlación entre la longitud (L) de las microlamelas de la serie 1 y el espesor (E) de éstas. El índice de correlación es de 0,48.

periférica engrosada, la lámina media está formada por gránulos aproximadamente isodiamétricos, cuyas dimensiones máximas no parecen sobrepasar las $18 \mu \mathrm{m}$, siendo los diámetros más frecuentes del orden de entre 7 y $14 \mu \mathrm{m}$ (Fig. 5A; Lám. III, figs. 1, 2). Aunque algo grandes, estas dimensiones coinciden con las que habitualmente se observan en los Tabulados.

En la parte media y externa de la zona periférica de las ramas maduras, los gránulos de la lámina media son reemplazados por (bio)cristales muy alargados, de 70-80 $\mu \mathrm{m}$ de longitud por un diámetro que puede alcanzar las $10 \mu \mathrm{m}$, los cuales presentan ocasionalmente una disposición ligeramente divergente (Fig. 3C). Este cambio corresponde a una fibrización periférica de la lámina media, ya señalada en Parastriatopora cantabrica (Tourneur y FernándezMartínez, 1991) y en ejemplares de Parastriatopora ex gr. annulata procedentes del sur de la Península Ibérica (Lafuste et al., 1992).

Zona de transición lámina media-estereoplasma s.s.

Entre la lámina media granular y las microlamelas del estereoplasma o los fibroides tectiformes que se describirán más adelante, pueden desarrollarse (por ejemplo, en los ejemplares CORD-PZ 9444 y 9453) elementos más 


\begin{tabular}{|l|c|c|c|}
\hline FUNCIONES & $\mathrm{L}$ & $\mathrm{H}$ & $\mathrm{E}$ \\
\hline & & & \\
\hline MEDIA & 34,63 & 15,02 & 12,33 \\
\hline MEDIANA & 33 & 15 & 12 \\
\hline RANGO & $16-65$ & $6-26$ & $4-24$ \\
\hline
\end{tabular}

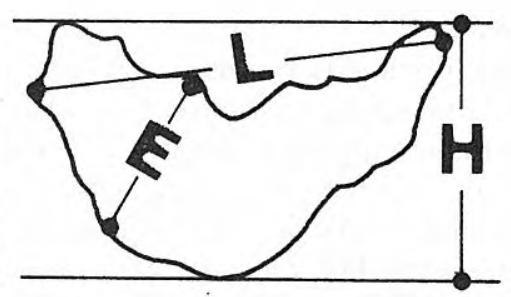

Tabla 3. Datos cuantitativos de las microlamelas $(\mathrm{en} \mu \mathrm{m})$. Los elementos microestructurales están caracterizados por tres dimensiones: longitud $(\mathrm{L})$, altura $(\mathrm{H})$ y anchura $(\mathrm{E})$, que pueden observarse en la figura anexa a la tabla. El número de medidas realizado ha sido de 95 para cada parámetro.

redondeados (de unas 20-25 $\mu \mathrm{m}$ de longitud por $10 \mu \mathrm{m}$ de diámetro los más gruesos). En cortes transversales, estos elementos aparecen como ortogonales a la lámina media (Fig. 5D) mientras que en secciones longitudinales muestran una ligera oblicuidad proximal (Fig. 5B). Dichos elementos pueden ser comparables a los gránulos estirados transversalmente que componen la lámina media de ciertos tabulados pero que, en este caso, no ocupan el plano medio de la pared.

En la zona axial de las ramas, la lámina media granular está flanqueada por un espesamiento que, en sección longitudinal, aparece constituido por cristales con disposición tectiforme (en diedro con divergencia proximal) (Figs. 5A, B). Su contorno es irregular y no muestran ni una cupulación particular ni una polaridad en sus indentaciones. La dimensión de estos cristales oscila entre 40-50 $\mu \mathrm{m}$ por 8$10 \mu \mathrm{m}$. En el caso de paredes muy delgadas, estos elementos no parecen estar recubiertos de estereoplasma, pero la zona de contacto entre el esqueleto y el cemento prismático precoz es siempre difícil de observar y una monocapa de microlamelas podría estar integrada en los cristales del cemento que tapizan el lumen de las coralitas. En el contacto entre la zona axial y la zona periférica, los elementos oblicuos están presentes pero parecen desarrollarse sólo sobre la cara interna de la muralla (Figs. 5B, D).

La naturaleza de estos elementos oblicuos, los cuales no han podido ser formalmente identificados en sección transversal, es mal conocida. A pesar de su orientación poco habitual y de sus grandes dimensiones (que pueden estar ligadas a fenómenos de recristalización), estos cristales recuerdan bien a los fibroides descritos en otros Tabulados: Thamnoptychia limbata (Lafuste, 1988), Saouraepora armoricana (Plusquellec et al., 1993) o Cystodendropora sinitzini (Plusquellec y Tourneur, inédito); o bien a la disposición tectiforme de las lamelas de Kiaerites (Lafuste y Tourneur, 1990). Es también reseñable que la disposición tectiforme aquí descrita se encuentra en Parastriatopora rhizoides, la especie tipo de este género (datos no publicados).

Independientemente de la importancia que se atribuya a los fenómenos diagenéticos, estos datos tienden a probar que en varias familias de Tabulados existe una zona intermedia entre la lámina media granular y el estereoplasma en su sentido estricto, pudiendo éste encontrarse formado por lamelas o microlamelas.

\section{Estereoplasma de pared y tábulas}

El estereoplasma en sentido estricto se encuentra particularmente desarrollado en la zona periférica de las ramas maduras y, por tanto, es aquí donde las observaciones son más fiables.

A grandes aumentos se observan monocristales de gran tamaño (más de $100 \mu \mathrm{m}$ de largo por 25-30 $\mu$ m de espesor máximo), sin forma bien definida pero cuya periferia dibuja siempre líneas cupulares, cuyo contorno muestra una concavidad dirigida en el sentido de acreción del esqueleto. Estas superficies monocristalinas se interpretan como resultantes de la recristalización de varios biocristales, de tal forma que, de las microlamelas originales, sólo subsisten trazas de algunas cúpulas en la periferia (Fig. 5E).

Al lado de estos monocristales, se observan grandes superficies constituidas por elementos más pequeños y con la morfología típica de las microlamelas. Se trata de cristales netamente arqueados, frecuentemente con la curvatura de la cara convexa (proximal) más acentuada que la de la cara cóncava (distal) y con una cupulación en general bien marcada (Figs. 5E, F; Lám. III, figs. 1, 2). Tanto la concavidad global como la concavidad de las cúpulas están orientadas hacia el pólipo, es decir, en el sentido de acreción del esqueleto.

\section{Morfología de las microlamelas}

El estudio detallado de las microlamelas ha permitido conocer las variaciones de tamaño y contorno que presentan y distinguir así varios tipos morfológicos. La panoplia de estas diferentes formas se presenta y describe en la Figura 6.

En el seno de este conjunto, hemos diferenciado dos series de objetos: 1) elementos considerados como microlamelas en sentido unitario y 2) elementos dudosos pero que podrían corresponder fácilmente a la fusión de varias microlamelas (ver leyenda de la Fig. 6). Del primero de estos conjuntos se ha realizado un estudio biométrico sencillo que comporta la obtención de las funciones estadísticas básicas (media, mediana y rango, Tabla 3) y de la correlación dos a dos entre los tres parámetros que tradicionalmente caracterizan los elementos microestructu-rales (longitud, altura y anchura, Fig. 7). La proximidad numérica entre la media y la mediana de cada parámetro indica que la muestra sigue una distribución normal. La correlación entre la longitud y la altura de cada microlamela $(0,65)$ es mayor que la existente entre la longitud y la anchura $(0,48)$, pero en ambos casos se trata de un grado de correlación alto que permite diferenciar las microlamelas seleccionadas como elementos con entidad propia. La altísima correlación entre la altura y la anchura de las microlamelas $(0,85)$ sugiere una repetición en la información aportada por estas medidas.

Las dimensiones de las microlamelas de Parastriatopora sanjuanina $\mathrm{n}$. sp. aparecen en la Tabla 3 y en las Figuras 6 y 
7. A grandes rasgos puede decirse que éstas son netamente superiores a las contabilizadas en las microlamelas clásicas (las presentes en la especie tipo, Parastriatopora rhizoides, por ejemplo) cuyo diámetro máximo es de aproximadamente 15-20 $\mu \mathrm{m}$. Por tanto, las microlamelas de la nueva especie de Parastriatopora pertenecen a la categoría de "grandes microlamelas" definidas en representantes devónicos de la familia Paleofavositidae por Plusquellec y Tourneur (1998). Es interesante señalar que en Parastriatopora cantabrica Tourneur y Fernández-Martínez, 1991, se han descrito microlamelas que alcanzan las 30-35 $\mu \mathrm{m}$ de diámetro.

\section{Disposición y organización de las microlamelas}

Globalmente, las grandes microlamelas se disponen de forma paralela entre sí, a la lámina media y a la superficie de las tábulas. En consecuencia, en el ángulo formado por una tábula y la pared adyacente o por dos lados de una muralla, se produce un brusco cambio de orientación que se manifiesta en una línea de enfrentamiento zigzagueante, ya señalada en el apartado de observaciones en láminas petrográficas.

Como se ha indicado, estas microlamelas se disponen de forma paralela entre sí pero, en la parte externa de la zona periférica de algunas ramas (CORD-PZ 9457, lámina LFP B43686), se observan localmente pequeños conjuntos de microlamelas orientados formando estructuras en zigzag. No existen evidencias que permitan atribuir dichas estructuras a fenómenos de recristalización.

\section{Conclusión sobre la microestructura}

Los ejemplares estudiados presentan las siguientes características: lámina media granular que pasa a ser fibrosa en la periferia de las ramas maduras; presencia, entre la lámina media $s$. $s$. y el estereoplasma de elementos transversales y/o de una capa de fibroides con disposición tectiforme; estereoplasma constituido por "grandes" microlamelas.

\section{Discusión}

Tal y como puede apreciarse en la diagnosis enmendada proporcionada por Tourneur y FernándezMartínez (1991), el género Parastriatopora muestra una amplia variabilidad de muchos de sus caracteres. Este hecho ha favorecido la inclusión dentro del mismo de formas muy alejadas de la especie tipo, Parastriatopora rhizoides Sokolov, dificultando así la atribución genérica. El problema se ve incrementado porque varias de estas especies han sido definidas con muy escaso material (su variabilidad intraespecífica nos es, por tanto, desconocida) o, en ocasiones, sin realizar un estudio detallado de la morfología externa de las ramas.

El material aquí descrito muestra los rasgos típicos de Parastriatopora según la diagnosis enmendada anteriormente citada: morfología cilíndrica de las ramas, coralitas que desembocan perpendicularmente a la superficie externa, engrosamientos periféricos de los difententes elementos esqueléticos y microestructura microlamelar. Además, comparte con muchas especies de este género la diferenciación neta entre la zona axial y el reborde periférico así como la presencia de cálices ornamentados por crestas.

Varias de las especies asignadas hasta la fecha a Parastriatopora muestran algunos rasgos próximos pero no idénticos a los del material argentino.

Parastriatopora marginata Dubatolov, 1969 del Devónico Inferior del nordeste de la antigua URSS tiene una zona axial de tamaño y constitución similar a la del material descrito, pero tanto las ramas como las coralitas de la especie rusa son de un tamaño menor. No existen figuraciones de la morfología externa pero, a juzgar por la periferia de las secciones en lámina delgada, los cálices parecen también mostrar un aspecto diferente.

Parastriatopora ertaensis Wang, 1983 del Devónico Medio del noroeste de China muestra, en las dos únicas figuras de la especie, un aspecto similar al del material argentino, con un reborde periférico marcado y aparentemente compacto y una zona axial pequeña, formada por muy pocas coralitas. Además, el tamaño tanto de las ramas como de las coralitas se aproxima al de las formas mayores aquí descritas. Es imposible conocer, con la figuración y diagnosis proporcionadas (no hay descripción), el verdadero alcance de esta especie. No obstante, las figuras permiten reconocer diferencias centradas principalmente en las coralitas de la zona axial, más escasas, de mayor tamaño y más iguales entre sí en la especie china que en el material argentino.

Dos especies argelinas de edad Lochkoviense, creadas por Le Maître (1952), P. floralis y P. annulata han sido también reconocidas en el Macizo Armoricano (Plusquellec, 1976) y en el sur de la Península Ibérica (Lafuste et al., 1992). Estas formas están integradas por ramas y zona axial de dimensiones similares a las del material argentino, con el que comparten así mismo el desarrollo de un reborde compacto y la ornamentación de las paredes calicinales, constituídas por crestas muy suaves separadas por depresiones puntiformes en la base del cáliz. Sin embargo, las formas argelinas tienen una ornamentación menos marcada y sencilla, con doce y no ocho depresiones puntiformes en el cáliz, así como coralitas de menor tamaño, paredes mucho más delgadas, poros sólo en las caras y un reborde periférico de desarrollo bastante más variable.

La comparación con formas similares procedentes de otras localidades de Sudamérica es también compleja porque gran parte del material conocido fue recolectado, someramente descrito y mal clasificado a principios de este siglo, perpetuándose posteriormente las citas erróneas. Los autores de este trabajo estamos realizando en la actualidad una revisión del material tipo de algunas de estas especies, así como de diversos ejemplares topotípicos procedentes de recolecciones modernas. Esta investigación en curso nos ha permitido comparar el material argentino aquí descrito con otras formas procedentes de Argentina y Bolivia.

La especie de coral tabulado más citada en Argentina es "Favosites argentina" Thomas, 1905, procedente de Cerro del Fuerte, en la parte norte de la Precordillera central. La revisión del material tipo y de diverso material topotípico de esta especie ha permitido constatar que no está relacionada con Favosites y que, con toda 
probabilidad se trata de un nuevo género más próximo pero diferente de Parastriatopora.

El material original de Parastriatopora gigantea (Knod, 1908), procedente del Devónico Medio de Yaco (Bolivia), así como otro material topotípico se encuentra pésimamente conservado, lo que impide estudiar muchos de sus caracteres. Aun así, pueden observarse diferencias notables entre las formas argentinas y bolivianas en el tamaño de ramas, constitución de la zona axial, desarrollo del reborde periférico y tamaño de las coralitas.

Otro material boliviano procede del Devónico Medio de la localidad de Pisacaviña y se encuentra en mejores condiciones de conservación. Estas formas han sido provisionalmente asignadas a Parastriapora gigantea (Tourneur, 1992), pero se trata probablemente de una nueva especie. Las ramas más pequeñas exhiben similitudes evidentes con los ejemplares argentinos de mayor tamaño, pero muestran algunos rasgos juveniles, como la desembocadura oblicua de los cálices y tienen, además, coralitas de mayor tamaño que las presentes en el material aquí descrito. La comparación de ambos conjuntos completos, boliviano y argentino, permite reconocer claras diferencias entre ambos aunque no puede descartarse algún tipo de relación entre estas faunas coralinas.

Teniendo en cuenta las limitaciones indicadas al principio de este apartado, puede concluirse que no se conoce ninguna especie de Parastriatopora de las descritas hasta la fecha dentro de cuya variabilidad pueda incluirse el material argentino aquí descrito. Se asigna, por tanto, a una nueva especie, posiblemente próxima a formas procedentes de Bolivia y que, hasta la revisión del material original de $P$. gigantea (actualmente en curso), habían sido atribuidas a esta especie. Por último, no puede descartarse la existencia de alguna relación con Parastriatopora ertaensis, pero la incompleta definición de esta especie china impide valorar dichas relaciones.

\section{AGRADECIMIENTOS}

Los autores deseamos expresar nuestro sincero agradecimiento a Santiago Falces, de la Universidad Complutense de Madrid, autor de dos magníficas láminas ultra-delgadas. Así mismo, agradecemos las sugerencias realizadas por los revisores del manuscrito original (Sergio Rodriguez, Graham Young y $\mathrm{M}^{\mathrm{a}}$. Luisa Martínez Chacón), las cuales han permitido mejorar considerablemente el mismo. Uno de los firmantes (E.F-M.) se ha beneficiado para la realización de este trabajo de una estancia en la Universidad de Bretaña Occidental (Francia) financiada por el Ministerio de Educación y Cultura de España. Este artículo es una contribución a los proyectos CONICOR 3475/95; CICYT PB-92-1008 y PICG 421.

\section{BIBLIOGRAFÍA}

Astini, R.A. 1991. Sedimentología de la Formación Talacasto: plataforma fangosa del Devónico precordillerano, Provincia de San Juan. Revista de la Asociación Geológica Argentina, 46 (3-4), 277-294.

Benedetto, J.L., Racheboeuf, P.R., Herrera, Z.A., Brussa, D. et Toro, B.A. 1992. Brachiopodes et biostratigraphie de la Formation de Los Espejos, Siluro-Dévonien de la Précordillère (NW Argentine). Geobios, 25, 599-637.

Dubatolov, V.N. 1969. [Tabulados y bioestratigrafía del Devónico Inferior del noroeste de la U.R.S.S.] (en ruso). Trudy Instituta Geologii $i$ Geofiziki, Akademia Nauka SSSR, Sibirskoe Otdelenie, 70, 1-179.

Edgecombe, G.D., Waisfeld, B.G. and Vaccari, N.E. 1994. Andinacaste (Trilobita) from the earliest Devonian of Argentina. Journal of Paleontology, 68, 837-841.

Fernández-Martínez, E., Salas, M.J., Herrera, Z., GarcíaLópez, S. y Plusquellec, Y. 1997. Presencia del coral tabulado Parastriatopora gigantea en el Devónico Inferior de Argentina. In: XIII Jornadas de Paleontología (Eds. A. Grandal d'Anglade, J. C. Gutiérrez Marco y L. Santos Fidalgo), 179-182.

García-López, S. and Fernández-Martínez, E. 1995. The genus Parastriatopora Sokolov, 1949 (Tabulata) in the Lower Devonian of Argentina: palaeobiogeographic implications. Geobios 28, 175-183.

Herrera, Z.A. 1991. Taxonomía, bioestratigrafía y paleobiogeografía de los braquiópodos de la Formación Talacasto (Devónico) de la Precordillera Argentina. Tesis Doctoral inédita., Universidad Nacional de Córdoba, 283 pp.

Herrera, Z.A. 1993. Nuevas precisiones sobre la edad de la Formación Talacasto (Precordillera argentina) en base a su fauna de braquiópodos. XII Congreso Geológico Argentino, 2, 289-295.

Herrera, Z.A. 1995a. The first Notanopliid Brachiopod from the South American Devonian sequence. Geobios, 28, 337-342.

Herrera, Z.A. 1995b. The Lower Devonian chonetoidean brachiopods from the Argentine Precordillera. In: Four contributions to the study of chonetoidean Brachiopods (Ed. P.R. Racheboeuf) Documents des Laboratoires de Géologie de Lyon, 136, 107-148.

Herrera, Z.A. y Racheboeuf, P. 1997. Afinidades paleobiogeográficas de la fauna de braquiópodos devónicos de la Precordillera Argentina. In: XIII Jornadas de Paleontología (Eds. A. Grandal d'Anglade, J. C. Gutiérrez Marco y L. Santos Fidalgo), 83-86.

Herrera, Z.A., Salas, M.J. y Giolitti, J.A. 1998. Chilidiopsoidea (Brachiopoda) del Devónico temprano de la Precordillera Argentina. Revista Española de Paleontología, 13, 149-166.

Knod, R. 1908. Devonischen Faunen Boliviens. In: Beiträge zur Geologie und Paläontologie von Südamerika unter Mittwirkung von Fachgenossen herausgegeben (Ed. G. Steinmann). Neues Jarhbuch für Geologie und Paläontologie, 25, 493-600.

Lafuste J. 1983. Disparité microstructurale entre Calceola Lamarck et Goniophyllum Dybowski (Tetracoralla, Dévonien et Silurien). Comptes Rendus Académie de Sciences Paris, 296, ser. II, 1749-1752.

Lafuste J. 1988. Microstructure de Thamnoptychia limbata (Eaton, 1832) Tabulata, Dévonien, Etat de New-York. Geobios, 21, 515-521. 
Lafuste, J. et Tourneur, F. 1990. Structure et microstructure du genre Kiaerites Stasinska, 1967 (Tabulata, Silurien de Norvège). Geobios, 23, 655-669.

Lafuste, J., Fernández-Martínez, E. y Tourneur, F. 1992. Parastriatopora (Tabulata) de las Calizas del Lorito (Devónico inferior, provincia de Córdoba): morfología y microestructura. Revista Española de Paleontología, 7, 3-12.

Le Hérissé, A., Rubinstein, C. and Steemans, P. 1997. Lower Devonian Palynomorphs from the Talacasto Formation, cerro del Fuerte section, San Juan Precordillera, Argentina. Acta Universitatis Carolinae, Geologica, 40, 497-515.

Le Maître, D. 1952. La faune du Dévonien inférieur et moyen de la Saoura et des abords de l'Erg el Djemel (Sud Oranais). Matériaux pour la Carte Géologique de l'Algérie, lère série, Paléontologie, 12, 1-170.

Plusquellec, Y. 1976. Les polypiers. Tabulata. In: Les Schistes et Calcaires éodévoniens de Saint-Céneré (Massif Armoricain, France). Sédimentologie, paléontologie, stratigraphie (Ed. H. Lardeux). Mémoires de la Société géologique et minéralogique de Bretagne, 97, 127-130.

Plusquellec, Y. et Tourneur, F. 1998. Persistence de Favositides microlamellaires (Cnidaria, Tabulata) dans le Dévonien. Comptes Rendus Académie de Sciences Paris, 326, 283-289.

Plusquellec, Y., Tourneur, F. et Lafuste, J. 1993. Saouraepora nouveau genre de Micheliniidae (Tabulata) du Dévonien du Nord Gondwana et du Carbonifère d'Amerique du Nord. Palaeontographica, Abt. A, 227, $1-86$.

Racheboeuf, P. and Herrera, Z.A. 1994. On some new Malvinokaffric Silurian and Devonian chonetacean brachiopods and reclassification of others. Neues Jahrbuch für Geologie und Paläontologie, 9, 541-560.
Salas, M. J. 1995. Estudio taxonómico y bioestratigráfico de la fauna de Braquiópodos devónicos en el área del Mogote La Cortadera (Sierra de la Deheza), Precordillera de San Juan. Trabajo de Licenciatura inédito. Universidad Nacional de Córdoba. 1-80.

Sokolov, B.S. 1955. [Tabulados paleozoicos de la parte europea de la U.R.S.S. Introducción al estudio general de la sistemática y desarrollo de los Tabulados] (en ruso). Trudy Vsesoyouznogo Neftianogo NautchnoIssledovatetskogo Geologorazvedotchnogo Instituta, n.s., $\mathbf{8 5}, 1-527$.

Thomas, I. 1905. Neue Beiträge zur Kenntnis der devonischen Fauna Argentiniens. Zeitschrift der Deutschen Geologischen Gessellschaft, 57, 233-290.

Tourneur, F. 1992. Présence du genre Parastriatopora Sokolov 1949 (Tabulata) dans le Dévonien supérieur de la Bolivie: implications paléogéographiques. Table ronde européenne "Paleontologie et Stratigraphie en Amerique Latine”, Lyon, 7-9 juillet, 1992, résumés, p. 47.

Tourneur, F. y Fernández-Martínez, E. 1991. Parastriatopora cantabrica, nueva especie de Tabulado del Devónico inferior (Emsiense) de la Cordillera Cantábrica (NO de España). Revista Española de Paleontología, 6, 3-19.

Vaccari, N.E., Waisfeld, B.G. and Edgecombe, G.D. 1994. Calmoniid trilobites of the Lower Devonian Scaphiocoelia Zone in the Argentine Precordillera. Geobios, 27, 591-608.

Waisfeld, B.G., Edgecombe, G.D. and Vaccari, N.E. 1994. Tormesiscus, a new blind calmoniid trilobite from the Lower Devonian, Argentine Precordillera. Geologica et Palaeontologica, 28, 27-43.

Wang Baoyu. 1983. [Atlas paleontológico del Noroeste de China. Volumen Xinjiang, parte 2. Paleozoico Superior] (en chino). Geological Publishing House, 217-250. 